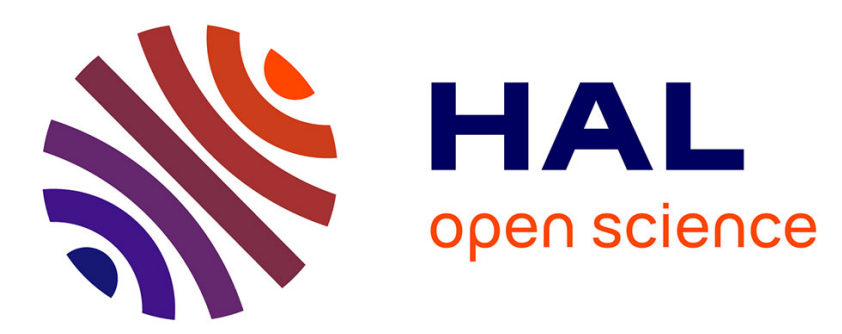

\title{
A person-centered perspective on the combined effects of global and specific LMX components for employees
}

Nicolas Gillet, Alexandre J. S. Morin, Baptiste Cougot, Lindsey Nadon, Evelyne Fouquereau

\section{- To cite this version:}

Nicolas Gillet, Alexandre J. S. Morin, Baptiste Cougot, Lindsey Nadon, Evelyne Fouquereau. A person-centered perspective on the combined effects of global and specific LMX components for employees. International Journal of Stress Management, 2022, 29 (1), pp.14-30. hal-03279701

\section{HAL Id: hal-03279701 \\ https://hal-univ-tours.archives-ouvertes.fr/hal-03279701}

Submitted on 6 Oct 2021

HAL is a multi-disciplinary open access archive for the deposit and dissemination of scientific research documents, whether they are published or not. The documents may come from teaching and research institutions in France or abroad, or from public or private research centers.
L'archive ouverte pluridisciplinaire HAL, est destinée au dépôt et à la diffusion de documents scientifiques de niveau recherche, publiés ou non, émanant des établissements d'enseignement et de recherche français ou étrangers, des laboratoires publics ou privés. 
Running Head: LMX Profiles

\title{
A Person-Centered Perspective on the Combined Effects of Global and Specific LMX Components for Employees
}

Nicolas Gillet*, Université de Tours, QualiPsy EE 1901, Tours, France

Institut Universitaire de France (IUF)

Alexandre J.S. Morin*, Substantive Methodological Synergy Research Laboratory, Department of Psychology, Concordia University, Montreal, Canada

Baptiste Cougot, Université de Tours, QualiPsy EE 1901, Tours, France

Lindsey Nadon, Substantive Methodological Synergy Research Laboratory, Department of Psychology, Concordia University, Montreal, Canada

Evelyne Fouquereau, Université de Tours, QualiPsy EE 1901, Tours, France

\author{
Corresponding author \\ Nicolas Gillet, \\ Université de Tours, \\ UFR Arts et Sciences Humaines, \\ Département de psychologie, \\ 3 rue des Tanneurs, 37041 Tours Cedex 1, France \\ E-mail: nicolas.gillet@univ-tours.fr
}

* The first two authors (N.G. \& A.J.S.M.) contributed equally to this article and their order was determined at random: Both should thus be considered first authors.

This is the prepublication version of the following manuscript:

Gillet, N., Morin, A. J. S, Cougot, B., Nadon, L., \& Fouquereau, E. (in press). A person-centered perspective on the combined effects of global and specific LMX components for employees. International Journal of Stress Management. Early view. DOI: 10.1037/str0000230

(C) 2021. This paper is not the copy of record and may not exactly replicate the authoritative document published in International Journal of Stress Management.

\begin{abstract}
The present study examines how the different dimensions of leader-member exchange (LMX) combine within different profiles of workers $(n=634)$. This research also documents the relations between LMX profiles and a series of demographic characteristics (gender, age, level of education, work schedule, organizational tenure, and tenure in the current position) and outcomes (affective commitment, well-being, emotional exhaustion, job satisfaction, positive and negative affect, and perceived health). Latent profile analyses revealed six profiles of employees defined based on their global and specific (loyalty, affect, contribution, and professional respect) levels of LMX: Low Exchange, Moderate Exchange with Low Affect, Normative, Moderately Low Exchange with High Loyalty and Low Respect, Moderate Exchange with High Affect and Low Respect, and Moderate Exchange with Low Loyalty and High Respect. Results also showed the least desirable levels on all outcomes to be associated with the Low Exchange profile, with most comparisons being statistically significant. In addition, the proportion of females was higher in the Low Exchange profile than in the Moderate Exchange with High Affect and Low Respect profile, while age and organizational tenure were unrelated to the likelihood of membership into any of the profiles.
\end{abstract}

Key words: Leader-member exchange; leadership; psychological health; organizational commitment; latent profile analyses; bifactor models 


\section{Introduction}

Although leaders are responsible for enacting a broad range of behaviors, leader-member exchange (LMX) is frequently treated as a unitary construct reflecting the quality of the exchange relationship between a leader and an employee (Rockstuhl et al., 2012). This representation implicitly assumes that the effects of LMX on various outcomes are consistent across the four LMX dimensions of loyalty, affect, contribution, and professional respect (Liden \& Maslyn, 1998). However, each of these LMX components focuses on fundamentally different aspects of leader-member relationships (Dienesch \& Liden, 1986). Thus, loyalty refers to the extent to which a supervisor publicly supports employees' actions and character. Affect reflects the affection employees have for their supervisor based primarily on interpersonal attraction. Contribution is defined as the perception of the level of work-oriented activity employees put forth toward the mutual goals of the dyad. Finally, professional respect reflects employees' perceptions of the degree to which a supervisor has built a reputation of excelling at work. Consistent with this perspective, Olsson et al. (2012) examined the links between LMX dimensions and creative performance in academic and commercial research groups. All LMX dimensions were found to be positively related to creative performance in the academic research groups, although some of these effects were not significant. In contrast, relations found in the commercial research groups were negative for affect and professional respect, and positive for loyalty and contribution. Olson et al. (2012) thus argued that the four LMX dimensions vary in the way they relate to different outcomes and across different work contexts.

Despite abundant research on the consequences of these four facets of LMX (Dienesch \& Liden, 1986; Liden \& Maslyn, 1998), very little is known about their combined impact (Kasekende, 2017). Two different approaches can be used to investigate the combined effect of LMX dimensions. Variable-centered analyses, mainly designed to test how a set of variables are able to play a complementary role in the prediction of other variables, have to rely on tests of interactions to account for non-additive effects. However, these approaches are unable to clearly depict the joint effect of variable combinations involving more than two or three interacting predictors, and become even more complex to interpret when relations display some non-linearity. In contrast, through their focus on the identification of subpopulations of employees characterized by distinct configurations, or profiles, on a set of variables, person-centered analyses are more naturally suited to the consideration of the joint effect of variable combinations without relying on any assumptions (e.g., linearity) in the shape of these relations and without relying on tests of interactions. As such, person-centered analyses are able to provide a complementary perspective (i.e., the flip side of the coin), focused on the most commonly occurring combinations among a set of variables, and the way these combinations relate to other variables.

To the best of our knowledge, no person-centered research has considered how LMX dimensions combine within specific individuals. Clearly, more research is needed to obtain a clearer picture of these LMX configurations, the factors influencing their development, and their effects on other work-related and health outcomes. Guided by the conservation of resources theory (Hobfoll, 1989), the present study seeks to fill this gap. More importantly, the present study does so while taking into account the inherent multidimensionality of LMX through the simultaneous consideration of employees' global and specific (loyalty, affect, contribution, and professional respect) levels of LMX. In addition, this study seeks to document the construct validity of the identified LMX profiles through the consideration of their associations with demographic characteristics (gender, age, level of education, work schedule, organizational tenure, and tenure in the current position) and outcome variables (affective commitment, well-being, emotional exhaustion, job satisfaction, positive and negative affect, and perceived health).

\section{On the Desirable Effects of Global LMX}

\section{The Critical Role of LMX}

The bulk of variable-centered studies conducted thus far supports the idea that LMX tends to be associated with a wide variety of positive consequences for employees (Rockstuhl et al., 2012). For instance, research has shown associations between LMX and higher levels of job satisfaction and affective commitment, and lower levels of emotional exhaustion and negative affect (Liao et al., 2017; Thomas \& Lankau, 2009). Many theoretical arguments have been proposed to account for these benefits of LMX. For instance, some have noted that LMX was positively related to trust and autonomy at work (Carnevale et al., 2017), as well as to positive affective responses during social interactions and more positive self-perceptions (Montano et al., 2017).

\section{The Differential Benefits of LMX Dimensions}

Liden and Maslyn (1998) provided initial support to the multidimensionality of the LMX construct, 
showing that each of the outcomes considered in their study was only associated to a subset of LMX dimensions, and that all LMX facets significantly predicted at least one of the outcomes. Thus, affect, loyalty, and professional respect (but not contribution) were significantly and positively related to satisfaction with supervision. Contribution and professional respect were also significantly and positively related to organizational commitment, while no statistically significant association was found for affect and loyalty. Moreover, Bang (2011) showed that affect and professional respect shared the strongest relations with volunteers' job satisfaction, while relations involving loyalty and contribution were not statistically significant. Similarly, Greguras and Ford (2006) showed that affect, loyalty, and professional respect (but not contribution) significantly and positively predicted satisfaction with supervision. Finally, contribution, professional respect, and affect (but not loyalty) significantly and positively predicted affective organizational commitment.

\section{An Integrated Representations of the Globality and Specificity of LMX}

Despite the recognition that a complete assessment of LMX should tap into the loyalty, affect, contribution, and professional respect components (Liden \& Maslyn, 1998), employees might perceive LMX in a more holistic manner as a single overarching LMX dimension (Rockstuhl et al., 2012). This global approach is supported by the observation of high correlations among ratings of loyalty, affect, contribution, and professional respect (Olsson et al., 2012). However, as noted above, research has also revealed well-differentiated meaningful associations between these four dimensions and a variety of outcome variables (Bang, 2011; Greguras \& Ford, 2006). These observations raise important questions related to: (a) whether loyalty, affect, contribution, and professional respect retain specificity over and above the assessment of the global LMX construct; and (b) whether this global LMX construct exists as an overarching entity including specificities mapped by the four facets, or whether these facets reflect distinct dimensions without a common core (Morin et al., 2016b, 2017).

In the current debate regarding whether LMX is best represented as a single global construct (Rockstuhl et al., 2012) or as conceptually-distinct subscales (Liden \& Maslyn, 1998), a third option exists according to which LMX might exist as a global entity reflecting commonalities among ratings of loyalty, affect, contribution, and professional respect, which themselves may include specificity unexplained by this global entity. Liden and Maslyn's (1998) higher-order results support the idea that ratings of loyalty, affect, contribution, and professional respect form conceptually-related dimensions of a global LMX construct. However, one remaining question is whether sufficient specificity exists in these four dimensions once global LMX is considered.

\section{The Combined Effects of LMX Dimensions}

More than three decades ago, Dienesch and Liden (1986) proposed that there may be betweenperson variability in the relative importance of each LMX dimension for different employees. Indeed, these four dimensions were not proposed to be mutually exclusive, but rather complementary (Liden \& Maslyn, 1998). Nevertheless, previous studies have mainly focused on the isolated effects of different LMX dimensions, leaving unknown the nature of the most commonly occurring LMX combinations, and the possible joint effects of these combinations. Among the few exceptions, Kasekende (2017) recently examined interactions between LMX dimensions in the prediction of perceptions of psychological contract fulfillment among Ugandan public service employees. Their results showed that the effects of affect and professional respect on employee's perceptions of psychological contract fulfillment were stronger when contribution was high. Although preliminary, this result highlights the possible value of considering LMX dimensions in combination, rather than in isolation.

\section{LMX Profiles}

Rather than focusing on how the effects of one dimension varies linearly as a function of another dimension, person-centered analyses directly consider the role played by the most commonly occurring LMX configurations. However, no person-centered research on LMX profiles has so far been conducted. Of particular relevance, the estimation of latent profiles based on indicators capturing the possible bifactor structure of LMX ratings (i.e., based on a proper disaggregation of global LMX levels from more specific LMX facets) would make it possible to identify clearer, and more easily interpretable, profiles differing from one another in relation to both the global component (i.e., global LMX) and to the more specific components (the four LMX dimensions) (Morin et al., 2016b, 2017). Importantly, ignoring this dual global/specific structure has caries the risk of identifying inaccurate profiles characterized by LMX levels solely capturing that global component and ignoring the more meaningful differences located at the specific facet level (Morin et al., 2016b, 2017). In this study, we 
apply this approach to the identification of LMX profiles.

The present study thus seeks to document LMX profiles defined based on global and specific levels of LMX. Importantly, by adopting an approach allowing us to differentiate the role played by employees' global levels of LMX relative to that played by each specific component, this study will help to verify the assertion that both components of LMX need to be considered to explain the role played by LMX components from an outcomes' perspective (Morin et al., 2016b, 2017). Due to the absence of prior person-centered research, it is difficult to specify hypotheses about the nature and number of the expected LMX profiles. However, in line with limited research relying on other leadership approaches (e.g., Chénard Poirier et al., 2017), it was expected that a relatively small number of profiles (i.e., between three and six) would be identified.

\section{An Inductive Methodology Guided by Theory}

Person-centered analyses are exploratory in nature (Meyer \& Morin, 2016). "Importantly, when dealing with new and emerging research methods allowing for a paradigmatic shift in how we see research questions, it is often simply not possible to devise clear-cut hypotheses regarding expected results, given the lack of any prior theoretical or empirical guidance" (Morin et al., 2018, pp. 807808). Repeated calls have also been made to encourage organizational research to become more open to exploratory investigations driven by research questions rather than directional hypotheses (e.g., Spector et al., 2014), a type of research that lends itself very well to the application of more inductive methodologies, such as person-centered analyses. Valuable research insights can emerge from the examination of well-supported research questions, even when it is impossible, due to lack of previous theoretical or empirical guidelines, to clearly specify the exact nature of the results that are expected (Morin et al., 2018). This study is a good example of the need for such an inductive approach given the lack of priori theorization, and empirical investigation, of a person-centered approach to LMX.

However, from a theoretical perspective, the conservation of resources theory (Hobfoll, 1989) is anchored into the assumption that employees seek to obtain, protect, and retain resources such as LMX. These resources are further purported to facilitate or enable the acquisition or preservation of additional resources. In sum, this theory suggests that resources, such as LMX components, do not typically exist in isolation, but tend to aggregate for specific profiles of employees to produce positive effects (Hobfoll, 1989). This perspective leads us to expect at least some profiles characterized by matching levels of LMX across dimensions such as, for example, a Normative profile with high global levels of LMX coupled with specific levels of loyalty, affect, contribution, and professional respect close to the sample average. This perspective is, however, somehow incomplete in that it positions job resources as environmental characteristics, thus neglecting the fact that LMX does emerge as a result of interactions between employees and their supervisors. Thus, when considering LMX as a resource, one also needs to consider that employees play an active role in shaping this specific resource. For this reason, it appears to be even more important to better understand the nature of emerging LMX profiles as a key prerequisite to further investigations of the individual and contextual mechanisms at play in their emergence.

Beyond these developmental considerations, the identification of LMX profiles should also allow us to identify whether all employees are exposed to consistent types of interactions with their supervisors across dimensions (i.e., profiles with high, average, or low levels across LMX dimensions), or whether some of them also experience inconsistent types of exchange relationships with their supervisors (i.e., profiles with levels that differ across LMX dimensions). Indeed, when considering the ever-changing and highly stressful work environment in which many employees and supervisors have to operate on a daily basis (Sparks et al., 2001), one can easily imagine that even a generally constructive leader may come to offer harsh and unjustified critics or reprimands to employees as a result of self-regulation impairments resulting from overwhelming job demands. Likewise, even a supervisor with clear dispositions toward low LMX may sometimes rely on positive motivational strategies, perhaps as an attempt to manipulate employees to better support him/her in attaining his/her personal objectives. Similarly, generally well-disposed employees can experience days in which the pressure get to them, resulting in perhaps harsher social exchanges with their supervisors, just like some more isolated employees can still manage to develop some form of positive exchanges with their supervisors. In all of these arguably plausible situations, employees would come to correspond to a LMX profile characterized by a more inconsistent LMX configuration.

In the leadership literature, it is well-documented that supervisors do not always act in a fully consistent manner toward their employees (Lian et al., 2012; Matta et al., 2017). Central to this inconsistency is the idea that whether supervisors (or employees) display high or low levels of LMX may not be entirely 
intentional or the sole product of dispositional traits, but might also depend on external factors that affect their ability to regulate their behaviors (Collins \& Jackson, 2015). It is important to acknowledge that this self-regulatory pathway is only one of the mechanisms which has been proposed to explain why some employees may come to experience different levels of LMX across dimensions. For instance, individuals with more constructive dispositions, such as those displaying high levels of agreeableness (Bono \& Judge, 2004), may be able to develop and maintain positive exchange relationships even when exposed to highly conflictual work contexts (Wang et al., 2010). Despite these various theoretical mechanisms, we are not aware of any study which has sought to identify the existence of profiles characterized by aligned, or misaligned, configurations of LMX components. Documenting the existence, nature, and implications of such profiles could be of the utmost importance for organizations seeking to maximize and support employees' and supervisors' positive attitudes (e.g., affective commitment, job satisfaction) and health.

\section{A Person-Centered Construct-Validation Perspective}

To document the theoretical and practical implications of the LMX profiles to be identified in this study, we adopt a construct validation perspective (Meyer \& Morin, 2016; Morin \& Wang, 2016) focused on documenting the associations between these profiles and a variety of covariates. This verification of construct validation is particularly important given the more indicative nature of the current study, which represents the first attempt at identifying LMX profiles.

\section{Demographic Characteristics and Their Associations with LMX Profiles}

We first focus on the possible associations between demographic characteristics (gender, age, level of education, work schedule, organizational tenure, and tenure in the current position) and profile membership. Jung and Takeuchi (2016) showed that gender and age were not significantly related to LMX. In contrast, employees with at least an undergraduate university degree reported lower levels of LMX than those with a high school diploma. However, a similar association between LMX and employees' levels of education has not been replicated in other studies (Lee, 2008). Additional research also reported a lack of associations between LMX levels and employees' gender, age, and organizational tenure (Collins et al., 2014; Kim et al., 2015; Lee, 2008). These considerations suggest that the demographic characteristics should be unrelated to the likelihood of membership into any of the profiles. Observing such a lack of relations would support the discriminant validity of the profiles. Outcomes of LMX Profiles

We also focus on outcome variables related to employees' attitudes (affective commitment, job satisfaction), psychological health (well-being, emotional exhaustion, positive and negative affect), and physical health (perceived health) known to present significant relations with LMX (Rockstuhl et al., 2012), although research leads to divergent conclusions regarding the relative importance of each dimension in the prediction of these outcomes (e.g., Greguras \& Ford, 2006; Liden \& Maslyn, 1998). Indeed, research suggests that the functional significance of one dimension (e.g., loyalty) could be greater than that of the others in the prediction of specific outcomes, leading us to expect welldifferentiated relations between profile membership and outcomes. Observing such relations would thus support both the convergent and discriminant validity of the profiles.

In addition to presenting well-documented links with LMX, these outcomes were selected based on mounting research evidence supporting their role in work performance (e.g., Gillet et al., 2013). For instance, employees' affective organizational commitment (Morin et al., 2011b, 2013) and job satisfaction (Flickinger et al., 2016; Kovacs et al., 2019) are both important predictors of job performance and intentions stay in the organization. Similarly, emotional exhaustion is another welldocumented predictor of work performance and persistence (Marchand \& Vandenberghe, 2016; Yagil $\&$ Medler-Liraz, 2017). Two distinct theoretical frameworks can help us to anticipate the nature of the associations to be expected among LMX profiles and the various outcomes considered here.

\section{Conservation of Resources Theory}

According to conservation of resources theory (Hobfoll, 1989), work-related resources, such LMX, should support the accumulation of additional individual (e.g., well-being and health) and work-related (e.g., affective commitment) resources among employees, allowing us to expect significant associations between the various LMX profiles and the outcomes considered in this study. This perspective is aligned with Kasekende's (2017) report of mutually reinforcing benefits associated with the combination of multiple LMX facets. However, beyond this generic expectation that more benefits should result from profiles characterized by higher LMX levels, the conservation of resources theory does not provide clear guidance regarding the likely effects of exposure to discrepant levels of LMX across dimensions. 


\section{The Within-Domain Exacerbation Phenomenon}

The within-domain exacerbation phenomenon has also been proposed to describe the undesirable effects of exposure to inconsistent interactions with supervisors who tend to rely on a combination of behaviors seen as both stressful and supportive by the employees (Major \& Zubek, 2017). This inconsistent combination of positive and negative social interactions involving the same individual is assumed to be even more harmful for exposed employees than exposure consistently problematic interactions with their supervisor (Hobman et al., 2009). This within-domain exacerbation phenomenon is assumed to stem from the negativity dominance principle, according to which "combinations of negative and positive entities yield evaluations that are more negative than the algebraic sum of individual subjective valences would predict" (Rozin \& Royzman, 2001, p. 296). One psychological mechanism that has been theoretically proposed to explain the within-domain exacerbation phenomenon is the uncertainty mechanism. This mechanism states that individuals strive to feel certainty about their world and their place in it (Lind \& van den Bos, 2002). Uncertainty arises when individuals struggle to predict their environment due to exposure to inconsistent behaviors. The uncertainty mechanism thus suggests that exposure to a profile characterized by an uncertain LMX configuration (i.e., combining high and low LMX across dimensions) should be more stressful than exposure to a consistently destructive exchange relationship, for two main reasons.

First, as a result of being exposed to inconsistent interactions with their supervisors, employees may feel a loss of control over their work environment (van den Bos \& Lind, 2002). Consistent exchange relationships, whether constructive or destructive, allow employees to better predict, control, and adapt to their environment. Considering the critical role of interactions with their supervisors in shaping and guiding employees' work, inconsistent exchange relationships may send mixed messages regarding what is valued, and what to expect, in the organization (Mullen et al., 2011). In this context, employees would have more difficulty knowing what and how important each of their goals are, and if they can count on their supervisor or not. This perceived lack of control is likely to act as an important stressor for exposed employees (Breevaart \& Bakker, 2014), and likely to impede their positive attitudes and well-being

Second, inconsistent exchange relationships also create relational uncertainty (De Cremer, 2003) and inform employees their relationship with their supervisor is unstable and malfunctioning (van den Bos \& Lind, 2002). Employees exposed to such relational uncertainty may come to question their worth, the quality of their contribution, and the quality of their exchange relationships. Multiple studies have shown that uncertain relationships tend to be more stressful than consistently aversive ones (Holt-Lunstad et al., 2003; Uchino et al., 2001). In addition, mixed messages can thwart employees' need to experience a coherent sense of self, leading to a threatening and disorienting feeling of self-uncertainty (De Cremer, 2003; Lind \& van den Bos, 2002), that could further impede their positive attitudes and well-being.

Taken together, these various theoretical considerations suggest the two following hypotheses.

Hypothesis 1: The highest levels of affective commitment, well-being, job satisfaction, positive affect, and perceived health should be associated with a profile characterized by high and consistent levels of LMX across dimensions, followed by a profile characterized by high but inconsistent levels of LMX across dimensions, then by a profile characterized by low and consistent levels of LMX across dimensions, and finally by a profile characterized by low but inconsistent levels of LMX across dimensions.

Hypothesis 2: The highest levels of emotional exhaustion and negative affect should be associated with a profile characterized by low but inconsistent levels of LMX across dimensions, followed by a profile characterized by low and consistent levels of LMX across dimensions, then by a profile characterized by high but inconsistent levels of LMX across dimensions, and finally by a profile characterized by high and consistent levels of LMX across dimensions.

\section{Participants and Procedures}

\section{Method}

A sample of 634 workers (207 men and 427 women) from various organizations (e.g., public hospitals, industries, sales, services) located in France participated in this study. Participants received a survey packet including the questionnaire, a cover letter explaining the objectives of the study, and a consent form stressing that participation was anonymous and voluntary. Questionnaires took approximately 20 minutes to complete, after which they were returned to research assistants. Respondents were aged between 19 and 63 years $(M=38.58, S D=11.05)$, had an average tenure of 11.30 years $(S D=10.31)$ in their organization and of 6.19 years $(S D=6.33)$ in their position. In terms of education, $1.4 \%$ of the participants had no diploma, $19.2 \%$ completed vocational training, $24.9 \%$ completed high school, and $54.5 \%$ completed university. Finally, $83.0 \%$ of the participants worked full-time. 


\section{Measures}

$\boldsymbol{L M X}$. LMX was assessed with a scale (Liden \& Maslyn, 1998) assessing the four dimensions of loyalty (4 items; $\alpha=.86$; e.g., "My supervisor defends my work actions to a superior, even without complete knowledge of the issue in question"), affect (4 items; $\alpha=.91$; e.g., "I like my supervisor very much as a person"), contribution ( 4 items; $\alpha=.78$; e.g., "I do work for my supervisor that goes beyond what is specified in my job description"), and professional respect ( 4 items; $\alpha=.90$; e.g., "I admire my supervisor's professional skills"). Items were rated on a 5-point scale (1 - strongly disagree; 5 - strongly agree).

Positive and negative affect. Positive ( 5 items; $\alpha=.69$; e.g., "determined") and negative ( 5 items, $\alpha=$ .76; e.g., "nervous") affect was assessed with the 10-item version of the Positive and Negative Affect Schedule (PANAS; Thompson, 2007; Watson et al., 1988). Participants were asked to rate how frequently they felt each affect using a 5-point scale (1 - never; 5 - always).

Emotional exhaustion. Emotional exhaustion was assessed with the 5-item subscale $(\alpha=.81$; e.g., "I feel emotionally drained by my work") from the Maslach Burnout Inventory-General Survey (Schaufeli et al., 1996). Items were rated on a 1 (strongly disagree) to 5 (strongly agree) scale.

Affective commitment to the organization. Meyer et al.'s (1993) scale was used to assess affective commitment to the organization ( 6 items, $\alpha=.92$; e.g., "I feel like part of the family at my organization"). Items were rated on a 5-point Likert-type scale ( 1 - strongly disagree; 5 - strongly agree).

Perceived health. Perceived health was assessed with four items $(\alpha=.83)$ based on the Medical Outcome Study (Stewart \& Ware, 1992): (a) "In general, would you say your health is excellent, very good, good, fair, or poor?" (from 1 - poor to 5 - excellent); (b) "To what extent do you have any particular health problems?" (from 1 - no extent to 5 - a very great extent); (c) "Thinking about the past 2 months, how much of the time has your health kept you from doing the kind of things other people your age do?" (from 1 - none of the time to 5 - all of the time); (d) "To what extent do you feel healthy enough to carry out things that you would like to do?" (from 1 - no extent to 5 - a very great extent). The scoring of the second and third items was reversed so that a higher score represents better health.

Job satisfaction. Job satisfaction was assessed with three items $(\alpha=.72$; e.g., "I am satisfied with my job") from the Michigan Organizational Assessment Questionnaire (Cammann et al., 1983). Items were rated on a 5-point Likert-type scale ( 1 - strongly disagree; 5 - strongly agree).

Well-being. Well-being was assessed with five items ( $\alpha=.77$; i.e., "ecstatic", "enthusiastic", "excited", "energetic", and "inspired") from the high pleasure/high arousal scale of the Job-related Affective Wellbeing Scale (Van Katwyk et al., 2000). Participants were asked to indicate how often they experienced each emotion in the past 30 days on a 5-point scale ranging from 1 (never) to 5 (always).

\section{Model Estimation}

\section{Analyses}

All analyses were conducted using Mplus 8 (Muthén \& Muthén, 2017) robust Maximum Likelihood (MLR) estimator. This estimator provides parameter estimates, standard errors, and fit indices that are robust to the non-normality of the response scales used in the present study (Finney \& DiStefano, 2013). These models were estimated with Full Information Maximum Likelihood (FIML; Enders, 2010) to handle the few missing responses present at the item level (0.00-0.79\%).

\section{Preliminary Analyses}

Our main analyses were estimated using factor scores saved from preliminary measurement models (Meyer \& Morin, 2016; Morin et al., 2016c). Factor scores provide a partial control for measurement errors (Skrondal \& Laake, 2001) and preserve the nature of the measurement model (Morin et al., 2016b, 2017). For the LMX measure, factor scores were saved from a bifactor confirmatory factor analytic model. Details on measurement models are reported in the online supplements.

\section{Person-Centered Analyses}

Latent profile analyses (LPA) including one to eight latent profiles were estimated allowing the means of the LMX factor scores (i.e., the profile indicators) to be freely estimated in all profiles. Despite the advantages of models in which the indicators' variances are also freely estimated (Diallo et al., 2016), these alternative models resulted in severe convergence difficulties, suggesting the superiority of our more parsimonious models (e.g., Chen et al., 2001). LPA were conducted using 5000 random sets of start values, 1000 iterations, and 200 final optimizations (Hipp \& Bauer, 2006).

The optimal number of profiles was selected by considering the substantive meaningfulness, theoretical conformity, and statistical adequacy of the solutions (Marsh et al., 2009; Morin, 2016). Statistical indices can help to guide this decision (McLachlan \& Peel, 2000): (i) the Akaïke 
Information Criterion (AIC), (ii) the Consistent AIC (CAIC), (iii) the Bayesian Information Criterion (BIC), (iv) the sample-size Adjusted BIC (ABIC), (v) the Integrated Classification Likelihood BIC (ICL-BIC: A BIC corrected for the model entropy, an indicator of the model classification accuracy), (vi) the standard and adjusted Lo, Mendell and Rubin's (2001) Likelihood Ratio Tests (LMR/aLMR; as these tests typically yield the same conclusions, we only report the aLMR), and (vii) the Bootstrap Likelihood Ratio Test (BLRT). A lower value on the AIC, CAIC, BIC, ABIC, and ICL-BIC suggests a better-fitting model. The aLMR and BLRT compare a $k$-class model with a $k$-1-class model. A significant $p$ value suggests that the $k$-1-class model may be rejected in favor of a $k$-class model.

A graphical display of five of these indicators (AIC, CAIC, BIC, ABIC, and ICL-BIC), referred to as an elbow plot, can also be examined (Morin, 2016; Morin et al., 2011a). In this elbow plot, the point at which these indicators appear to reach a plateau can be used to guide the selection of the optimal solution. Once these various sources of statistical information are considered, the typical recommendation is that the solution(s) thus suggested, together with the adjacent solutions including one fewer and one more profile, should be more precisely examined for theoretical conformity, meaningfulness, and to locate more precisely the point at which adding profiles to the solution ceases to bring new information (e.g., Marsh et al., 2009; Meyer \& Morin, 2016; Morin, 2016).

\section{Covariates of Profile Membership}

The profiles were contrasted on demographics (gender, age, education, schedule, organizational tenure, and tenure in the current position) and outcomes (affective commitment, well-being, emotional exhaustion, job satisfaction, positive and negative affect, and perceived health) using an approach proposed by Lanza et al. (2013), implemented using the Auxiliary (DCON) function (Asparouhov \& Muthén, 2014). Outcomes were incorporated in a single analytic step as factor scores taken from a preliminary model (see Table S3 of the online supplements; composite reliability was satisfactory for all variables with $\omega=.797$ to .943). Correlations among all variables are reported in Table 1 .

\section{Latent Profile Solutions}

\section{Results}

The fit indices of the alternative LPA estimated in this study are reported in Table 2. The ICL-BIC reached its lowest point at 7 profiles. In contrast, all other information criteria kept on suggesting the addition of profiles up to the 8-profile solution. Even the elbow plot associated with these solutions remained unclear (Figure S1 of the online supplements), revealing that the decrease in the value of these information criteria reached a plateau after 4 (CAIC, BIC) or 5 (ABIC) profiles. Based on these observations, we carefully examined solutions including 4 to 7 profiles, which were all fully proper statistically. This examination revealed that moving from 4 to 5 profiles and from 5 to 6 profiles resulted in the addition of a meaningfully distinct profile to the solution (respectively corresponding to the fourth and sixth profiles illustrated in Figure 1), whereas adding a seventh profile resulted into the arbitrary division of an existing profile (the sixth profile from Figure 1) into two similar, but much smaller profiles (the smallest corresponded to less than 10 participants). The 6-profile solution was thus retained and is graphically illustrated in Figure 1 (detailed results appear in Tables S4 and S5 of the online supplements). The results revealed a high classification accuracy of participants into their most likely profile, ranging from $76.4 \%$ to $82.9 \%$ across profiles.

In this solution, a first noteworthy observation lies in the identification of a Normative profile (Profile 3), representing $47.32 \%$ of the employees. The label Normative was retained to reflect the fact that this profile not only characterized almost half of the sample, but also reflected a subpopulation of employees whose global levels of LMX was moderately high, and coupled with specific levels of loyalty, affect, contribution, and professional respect close to the sample average. This profile shows that most employees display a satisfactory global LMX balanced across all four dimensions.

In contrast, the remaining profiles were characterized by lower (moderate to low) global levels of LMX, and imbalance (or misalignment) among specific LMX components. Thus, Profile 1 was characterized by the lowest global levels of LMX, and by moderate to moderately low levels of affect, loyalty, contribution, and professional respect. This Low Exchange profile characterized $10.10 \%$ of the employees. In contrast, Profile 2 was characterized by average levels of global LMX and contribution, by low levels of affect, and by moderately high levels of loyalty and professional respect. This Moderate Exchange with Low Affect profile characterized 13.41\% of the employees. Profile 4 was characterized by low levels of global LMX and professional respect, by moderately low levels of affect, by average levels of contribution, and by high levels of loyalty. This Moderately Low Exchange 
with High Loyalty and Low Respect profile characterized $6.78 \%$ of the employees. Profile 5 was characterized by average levels of global LMX and loyalty, by moderately low levels of contribution, by low levels of professional respect, and by high levels of affect. This Moderate Exchange with High Affect and Low Respect profile characterized 14.35\% of the employees. Finally, Profile 6 was characterized by average levels of global LMX, affect, and contribution, by low levels of loyalty, and by high levels of professional respect. This Moderate Exchange with Low Loyalty and High Respect profile characterized $8.04 \%$ of the employees.

\section{Covariates of Profile Membership}

Associations between the profiles and the demographic characteristics and outcome variables are reported in Table 3, and profile-specific outcome levels are graphically illustrated in Figures 2 (affective commitment, well-being, and job satisfaction) and 3 (positive affect, perceived health, emotional exhaustion, and negative affect). The proportion of females was higher in the Low Exchange (1) profile than in the Moderate Exchange with High Affect and Low Respect (5) profile. The level of education was lower in the Moderately Low Exchange with High Loyalty and Low Respect (4) profile than in the Low Exchange (1), Moderate Exchange with Low Affect (2), Normative (3), and Moderate Exchange with Low Loyalty and High Respect (6) profiles which could not be differentiated from one another. In addition, the level of education was lower in the Low Exchange (1) profile than in the Moderate Exchange with High Affect and Low Respect (5) profile. The proportion of full-time employees was higher in the Moderate Exchange with Low Affect (2) profile than in the Normative (3) and Moderate Exchange with Low Loyalty and High Respect (6) profiles which could not be differentiated from one another. Tenure in the position was higher in the Moderately Low Exchange with High Loyalty and Low Respect (4) and Moderate Exchange with High Affect and Low Respect (5) profiles (which could not be differentiated from one another) than in in the Moderate Exchange with Low Affect (2), Normative (3), and Moderate Exchange with Low Loyalty and High Respect (6) profiles (which could not be differentiated from one another). Finally, age and organizational tenure were unrelated to profile membership.

The highest levels of affective commitment were observed in the Normative (3) profile, followed equally by the Moderate Exchange with Low Affect (2) and Moderate Exchange with Low Loyalty and High Respect (6) profiles, and finally by the Low Exchange (1), Moderately Low Exchange with High Loyalty and Low Respect (4), and Moderate Exchange with High Affect and Low Respect (5) profiles which could not be differentiated from one another. The highest levels of well-being and job satisfaction were associated with the Normative (3) profile, followed equally by the Moderate Exchange with Low Affect (2), Moderately Low Exchange with High Loyalty and Low Respect (4), Moderate Exchange with High Affect and Low Respect (5), and Moderate Exchange with Low Loyalty and High Respect (6) profiles, and finally by the Low Exchange (1) profile.

The Low Exchange (1) profile was associated with lower levels of positive affect than the Normative (3), Moderately Low Exchange with High Loyalty and Low Respect (4), and Moderate Exchange with Low Loyalty and High Respect (6) profiles. The Moderate Exchange with High Affect and Low Respect (5) profile was associated with higher levels of perceived health than the Low Exchange (1), Moderate Exchange with Low Affect (2), and Moderate Exchange with Low Loyalty and High Respect (6) profiles which could not be differentiated from one another. In addition, the Moderate Exchange with Low Loyalty and High Respect (6) profile was associated with lower levels of perceived health than the Normative (3) and Moderately Low Exchange with High Loyalty and Low Respect (4) profiles which could not be differentiated from one another.

The highest levels of emotional exhaustion were associated with the Low Exchange (1) profile, followed by the Moderate Exchange with Low Loyalty and High Respect (6) profile, by the Moderate Exchange with Low Affect (2) profile, and finally by the Normative (3), Moderately Low Exchange with High Loyalty and Low Respect (4), and Moderate Exchange with High Affect and Low Respect (5) profiles which could not be differentiated from one another. The highest levels of negative affect were associated with the Low Exchange (1) and Moderate Exchange with Low Loyalty and High Respect (6) profiles which could not be differentiated from one another, followed by the Moderate Exchange with Low Affect (2) profile, and finally by the Normative (3), Moderately Low Exchange with High Loyalty and Low Respect (4), and Moderate Exchange with High Affect and Low Respect (5) profiles which could not be differentiated from one another.

Taken together, these results globally support Hypotheses 1 and 2. To facilitate integration of all 
results, we provide a comprehensive summary in Table 4.

\section{Discussion}

Despite the recognition of the interrelated nature of the four facets of LMX (i.e., loyalty, affect, contribution, and professional respect; Liden \& Maslyn, 1998), the ways into which these components are combined among specific subpopulations, or profiles, of employees had never been investigated in the work context. The present study was designed to address this issue, while relying on a bifactor approach to achieve a more precise disaggregation of global LMX levels from the levels of more specific LMX dimensions (loyalty, affect, contribution, and professional respect (Morin et al., 2016b, 2017). The present study also sought to document their practical and theoretical relevance through a consideration of their associations with a series of demographic characteristics (gender, age, level of education, work schedule, organizational tenure, and tenure in the current position), attitudes (affective commitment, job satisfaction), and psychological (well-being, emotional exhaustion, positive and negative affect) and physical (perceived health) health indicators.

\section{Characteristics of LMX Profiles}

The results revealed six distinct profiles of employees: Low Exchange (1), Moderate Exchange with Low Affect (2), Normative (3), Moderately Low Exchange with High Loyalty and Low Respect (4), Moderate Exchange with High Affect and Low Respect (5), and Moderate Exchange with Low Loyalty and High Respect (6) configurations. Results also showed that profiles characterized by moderate global levels of LMX (Moderate Exchange with Low Affect, Moderately Low Exchange with High Loyalty and Low Respect, Moderate Exchange with High Affect and Low Respect, and Moderate Exchange with Low Loyalty and High Respect) presented a more imbalanced configuration where specific levels of LMX tended to deviate more from the sample average. In contrast, the Normative profile, characterized by moderately high global levels of LMX, presented a more balanced configuration where specific levels of LMX were aligned with one another and with the sample average. In particular, the identification of such a large (47.32\%) Normative profile suggests that, for almost half of the present sample, global levels of LMX remain satisfactory and aligned across all four components. This result is concordant with prior investigations which also identified a dominant Normative profile characterized by moderate levels of work engagement (Gillet et al., 2019a), wellbeing (Morin et al., 2016b, 2017) or need satisfaction (Gillet et al., 2019b). Contrasting with this Normative profile, members of the Low Exchange profile were characterized by low global levels of LMX and moderate to moderately low levels of affect, loyalty, contribution, and professional respect. In this profile, although imbalance was present to some extent, it remained minimal.

Imbalance in specific, relative to global, levels of LMX were far more evident in profiles characterized by moderate to moderately low global levels of LMX. Thus, members of the Moderate Exchange with Low Affect profile were characterized by average levels of global LMX and generally describe their supervisors as loyal to them (i.e., loyalty), report being motivated to contribute above standards by their supervisor (i.e., contribution), and respecting their supervisors expertise at work (respect). However, they also mention not appreciating their supervisor as a person (i.e., affect). The remaining profiles are even more contrasted. Thus, members of the Moderately Low Exchange with High Loyalty and Low Respect profile were characterized by generally low levels of global LMX, and reported a misalignment in LMX dimensions indicating a perception of their supervisor as being very loyal to them, but someone not deserving their respect professionally. In contrast, members of the Moderate Exchange with Low Loyalty and High Respect profile are the diametrical opposite, characterized by moderate levels of LMX coupled with perceptions of their supervisors as not being loyal to them but deserving of their respect professionally. Finally, members of the Moderate Exchange with High Affect and Low Respect profile are also characterized by moderate levels of LMX and report appreciating their supervisors as persons while lacking respect for them professionally.

These profiles were identified using five indicators reflecting global levels of LMX, as well as specific levels of loyalty, affect, contribution, and professional respect. Support from this operationalization came from preliminary analyses. Importantly, these preliminary results suggested that LMX cannot be reduced to a single dimension, nor can it be represented as a collection of distinct, yet interrelated, facets. Rather, LMX seems to maximally benefit from an operationalization simultaneously covering both possibilities, allowing one to obtain a clearer disaggregation of effects attributable to global LMX levels from those stemming from discrepancies between these global levels and specific levels of loyalty, affect, contribution, and professional respect. It would be interesting for 
future research to assess more extensively the situations, occupations, and professional contexts which may lead to more or less frequent degrees of misalignment between employees' global ratings of LMX and their specific ratings of loyalty, affect, contribution, and professional respect.

\section{Demographic Characteristics and LMX Profiles}

To achieve a better understanding of the nature of employees corresponding to each profile, we considered their associations with participants' demographic characteristics. Although prior variablecentered studies have addressed the associations between demographic characteristics and LMX in various contexts (e.g., Collins et al., 2014), no research had yet been conducted to analyze how these factors relate to the likelihood of membership into multidimensional LMX profiles. It is noteworthy that, in accordance with the results from previous studies reporting only limited associations between demographic characteristics and LMX (e.g., Collins et al., 2014; Kim et al., 2015), few associations were observed between gender, education levels, work schedule or tenure in the current position and profile membership, and none between age or organizational tenure and profile membership.

Among the few exceptions, full-time workers were more likely to display low specific levels of affect (Moderate Exchange with Low Affect) relative to a Normative or Moderate Exchange with Low Loyalty and High Respect profile. Indeed, with a full time positon, workers have more time to accumulate task-related knowledge and skills, and to gain higher autonomy in their job, thus leading to less frequent interactions with their supervisor and lower interpersonal attraction (Marchese \& Ryan, 2001). In addition, the results showed that employees with low levels of education were more likely to display low global levels of LMX coupled with high specific levels of loyalty (Moderately Low Exchange with High Loyalty and Low Respect). These results suggest that employees with lower levels of education tend to perceive their leaders as being more loyal to them, and thus more likely to publicly support them. This result is concordant with previous results showing that supervisor support can be used as a mechanism to support more vulnerable employees (Honkavuo \& Lindström, 2014).

Similarly, more experienced employees were more likely to display a Moderately Low Exchange with High Loyalty and Low Respect profile or a Moderate Exchange with High Affect and Low Respect profile. These results suggest that more experienced workers tend to perceive their supervisor as lacking in terms of work efficiency, while being able to differentially see them as being strong supporters or at least agreeable as individuals. Finally, our results showed that female employees were more likely to display a Low Exchange profile relative to a Moderate Exchange with High Affect and Low Respect profile. This difference is consistent with prior research demonstrating that women tend to display lower LMX levels than men (Collins et al., 2014) and indicating that women tend to feel less supported by their supervisors relative to men (Paustian-Underdahl et al., 2017). However, it is true that the present study relied on a sample characterized by a majority of women (67.4\%), thus limiting the generalizability of our results and suggesting that future research will be needed to more systematically investigate sex and gender differences in profile membership.

\section{Outcomes of LMX Profiles}

Our results showed that the profiles displayed well-differentiated associations with all outcomes. These results revealed associations that matched the results from previous variable-centered research (Carnevale et al., 2017; Rockstuhl et al., 2012) and supported our hypotheses in confirming the role of global and specific levels of LMX. Indeed, employees with the highest levels of global LMX (Normative profile) coupled with aligned levels of LMX across dimensions, displayed the most adaptive functioning (i.e., the highest levels of affective commitment, well-being, and job satisfaction). In contrast, employees with the lowest global LMX (Low Exchange profile) coupled with a generally misaligned configuration, displayed the least desirable outcome levels (e.g., the highest emotional exhaustion, and the lowest well-being, job satisfaction, and positive affect). These results first seem to match Liden and Maslyn's (1998) proposition that high levels of loyalty, affect, contribution, and professional respect are essential for experiencing positive outcomes, a proposal that has been supported in many studies using a variety of outcomes (e.g., Bang, 2011; Greguras \& Ford, 2006). Importantly, these results help to expand our understanding of the within-domain exacerbation phenomenon, by showing that profiles characterized by high and consistent levels of LMX across dimensions tend to be associated with more desirable outcomes than more imbalanced profiles. This suggests that employees sharing an exchange relationship with their supervisor that inconsistently acts as a source of stress and support could interfere with employees' positive attitudes and health. Indeed, when confronted with hard to anticipate inconsistent interactions with their supervisors, followers may 
come to feel uncertainty due to their incapacity to properly anticipate and control their environment, their relationship with their supervisor, and their perception of themselves (Lind \& van den Bos, 2002; van den Bos \& Lind, 2002). These forms of uncertainty could then make it harder for exposed employees to devise efficient coping strategies (Uchino et al., 2001).

Beyond their contribution to our understanding of the within-domain exacerbation phenomenon, these results are particularly interesting given the fact that balance among LMX components has never received scientific attention before the present study. Yet, our results match those found in other research areas. For example, in self-determination theory, results have also shown that a balanced level of psychological need satisfaction played a critical role for human adaptation (e.g., Gillet et al., 2019b). Likewise, our results are also aligned with research on the effects of work-life balance on individual and organizational functioning (Barber et al., 2016). According to the scarcity hypothesis (Goode, 1960), people have a limited amount of time and energy to devote to different areas in their lives (e.g., work, family). The allocation of these resources to certain life domains leaves less time and energy for other domains. Thus, when the allocation of these resources is imbalanced across domains, insufficient time and energy can be allocated to some important areas, creating stress and conflict that lead to detrimental outcomes (Barber et al., 2016). Our study suggests that a similar form of balance in relation to employees' exchange relationships with their supervisors also seems to be important.

In addition to supporting the benefits of balance among LMX components, our results confirmed prior research results (Rockstuhl et al., 2012), in demonstrating the role of the global levels of LMX observed within each profile as a core driver of outcome associations. This result in aligned with the LMX research literature showing that when employees cannot develop high-quality exchange relationships with their supervisor, they may come to experience some deficit in relation to the resources that are necessary (e.g., trust and autonomy: Carnevale et al., 2017) for their well-being, thereby becoming more likely to experience adverse consequences (Thomas \& Lankau, 2009).

Finally, beyond this preeminent role of global LMX levels, our results also highlighted the role of the specific LMX dimensions, particularly respect and loyalty, in the prediction of the outcomes. More specifically, the Moderately Low Exchange with High Loyalty and Low Respect profile, as well as the Moderate Exchange with High Affect and Low Respect profile both presented similarly low levels of affective commitment. Thus, experiencing a lack of respect for one's supervisor (irrespective of loyalty or affection) appears to carry as much risk in terms of reducing affective commitment as experiencing globally low levels of LMX, and to be a key driver of reductions in affective commitment levels. In contrast, the Low Exchange profile and the Moderate Exchange with Low Loyalty and High Respect profile presented similarly high levels of negative affect, suggesting a key impact of exposure to a lack of supervisor loyalty on the emergence of negative affect at work.

Moreover, the desirable levels of emotional exhaustion (low), negative (low) and positive (high) affect, and perceived health (high) observed in the Normative profile were found to be impossible to distinguish from those observed in the Moderately Low Exchange with High Loyalty and Low Respect profile and in the Moderate Exchange with High Affect and Low Respect profile. Further supporting the importance of supervisor loyalty, levels of emotional exhaustion observed in the Moderate Exchange with Low Loyalty and High Respect profile were higher than those observed in the Moderate Exchange with Low Affect one. These results support those from previous variable-centered research (Greguras \& Ford, 2006; Liden \& Maslyn, 1998) in suggesting that loyalty seems to be particularly important to the prediction of positive emotional states.

Indeed, loyalty is a core aspect of professional identity that may help in addressing tensions between supervisors and subordinates (Hart \& Thompson, 2007). Specifically, when supervisors publicly support their followers in their interactions with others, employees have the opportunity to satisfy their basic psychological needs for autonomy, competence, and relatedness (Gillet et al., 2018a), and come to see their supervisors as fulfilling their obligation toward them (Doden et al., 2018). However, the Normative profile also presented higher levels of affective commitment, wellbeing, and job satisfaction than these other profiles, again supporting the risks of reporting a lack of professional respect for one's supervisor. Indeed, when workers perceive their supervisor as excellent and competent at work, they feel that their leader is trustworthy. Yet, trust is an essential factor of organizational and individual effectiveness (Searle et al., 2011) and past research showed that positive trust in leaders is associated with adaptive outcomes (e.g., Chughtai et al., 2015).

These results also confirm the value of considering both global and specific components when 
studying the implications of LMX profiles. Our results highlight that failure to consider the possibility that LMX ratings may simultaneously tap into these global and specific components is likely to erroneously lead to the conclusion that loyalty, affect, contribution, and professional respect are relatively independent constructs with comparable effects. These comparable effects would mainly reflect the underlying role of employees' global levels of LMX, and hide the complementary effects of the specific factors. Ignoring this form of multidimensionality is thus likely to lead to a biased view of the validity of the LMX construct and of the reality under study. This means that the ability to obtain a clear and valid estimate of the way LMX ratings related to other constructs of interest is likely to be biased, and more importantly to lead to biased recommendations for practice. Furthermore, our results also suggest that the effects described above differ importantly across outcomes. This observation reinforces the importance for future research to consider a broader range of desirable (e.g., organizational citizenship behaviors, job performance) and undesirable (e.g., turnover, work-family conflict) outcomes to better understand the mechanisms at play in explaining these differential effects.

\section{Limitations and Directions for Future Research}

This study presents some limitations worth noting. First, we relied on self-report measures, which may have been impacted by social desirability and self-report biases. Future research should consider relying on more objective indicators of individual and organizational functioning (e.g., performance, turnover) together with informant-reported (e.g., spouse) measures of work-family conflict. Second, the present study relied on a convenience sample of French workers, which cannot be considered to be representative of the population of French workers. Moreover, information was not available to allow us to investigate the associations between employees' occupations, or industry sector, and profile membership. This is unfortunate given the fact that these characteristics have been previously shown to be associated with profile membership in other areas of research (e.g., Fouquereau et al., 2019). Thus, additional person-centered research should be conducted to assess the generalizability of the identified profiles and of their associations with covariates, across distinct samples of employees (e.g., teleworkers, managers), types of industry, and in different cultures and countries (Morin et al., 2016c).

Third, we interpreted the associations between the LMX profiles and covariates considered as outcomes based on a theoretical rationale (Liden \& Maslyn, 1998). However, our study design did not allow us to assess reversed causality, reciprocal influence, or spurious associations, nor the possible role of profile membership in the prediction of changes in outcome levels. Therefore, future longitudinal research would gain from examining more systematically the direction of the associations among covariates and profiles within the context of a longitudinal research design. Indeed, longitudinal research makes it possible to address the joint issues of within-person and within-sample profile stability (Gillet et al., 2017; Kam et al., 2016). Future research may also consider the possible mechanisms at play in explaining these potential profile transitions. Finally, we only looked into the links between demographic characteristics and LMX profiles. Yet, it would be worthwhile for future research to investigate other determinants inherent to the work environment (e.g., organizational climate) or individual orientations (i.e., motivation, perfectionism).

\section{Practical Implications}

Our research emphasizes that organizations and managers could gain by adopting practices and behaviors seeking to promote higher levels of LMX among employees, and to nurture LMX for employees displaying low LMX levels. Indeed, these individuals characterized by the lowest levels of LMX are exposed to higher risks of maladaptive functioning (e.g., low job satisfaction, high emotional exhaustion). Employees characterized by moderate global levels of LMX coupled with a misalignment in their perceptions of respect (high levels) and loyalty (low levels) present high levels of emotional exhaustion and negative affect. Organizations should thus encourage, train, and provide necessary support for leaders to develop high-quality relationships with their employees.

For instance, supervisors should encourage their subordinates to take on job demands and offer them sufficient support (Lam et al., 2018). More specifically, they could give them clear guidance and share their experience in terms of how to handle challenges at work. They can also cultivate a safe climate for their employees to handle challenges at work in a creative manner. Interestingly, Eisenberger et al. (2014) showed that perceived organizational support was associated with higher levels of LMX. Yet, organizational practices such as fairness and recognition are positively related to perceived organizational support (Gillet et al., 2018b) and therefore could be used to increase the level of LMX. Other work experiences can also facilitate the development of perceived organizational 
support, thus indirectly enhancing the quality of supervisors' exchange relationship with subordinates, such as supportive human resource practices (Rhoades \& Eisenberger, 2002).

In addition, human resources departments should design leadership training programs to help their managers realize the important role of high LMX in building a thriving workforce and equip them with relevant skills to do so. Meanwhile, considering that leaders may have limited time and resources to maintain high-quality relationships with each follower, human resources departments could provide learning opportunities and socio-emotional support for their employees directly (Xu et al., 2019). Such training would promote the understanding that leaders can use social exchange to meet performance demands and accommodating worker work-life balance needs (Morganson et al., 2017).

\section{References}

Asparouhov, T., \& Muthén, B. (2014). Auxiliary variables in mixture modeling: Three-step approaches using Mplus. Structural Equation Modeling, 21, 329-341.

Bang, H. (2011). Leader-member exchange in nonprofit sport organizations: The impact on job satisfaction and intention to stay from the perspectives of volunteer leaders and followers. Nonprofit Management and Leadership, 22, 85-105.

Barber, L.K., Grawitch, M.J., \& Maloney, P.W. (2016). Work-life balance: Contemporary perspectives. In M.J. Grawitch \& D. W. Ballard (Eds.), The psychologically healthy workplace: Building a win-win environment for organizations and employees (pp. 111-133). American Psychological Association.

Bono, J.E., \& Judge, T.A. (2004). Personality and transformational and transactional leadership: A meta-analysis. Journal of Applied Psychology, 89, 901-910.

Breevaart, K., \& Bakker, A.B. (2014). The influence of constructive and destructive leadership behaviors on follower burnout. In M. Leiter, A.B. Bakker, \& C. Maslach (Eds.), Burnout at work (pp. 110-129). Psychology Press.

Cammann, C., Fichman, M., Jenkins, G.D., \& Klesh, J. (1983). Michigan Organizational Assessment Questionnaire. In S.E. Seashore, E.E. Lawler, P.H. Mirvis, \& C. Cammann (Eds.), Assessing organizational change (pp. 71-138). Wiley.

Carnevale, J.B., Huang, L., Crede, M., Harms, P., \& Uhl-Bien, M. (2017). Leading to stimulate employees' ideas: A quantitative review of leader-member exchange, employee voice, creativity, and innovative behavior. Applied Psychology: An International Review, 66, 517-552.

Chen, F., Bollen, K.A., Paxton, P., Curran, P.J., \& Kirby, J.B. (2001). Improper solutions in structural models: Causes, consequences, and strategies. Sociological Methods \& Research, 29, 468-508.

Chénard Poirier, L.-A., Morin, A.J.S., \& Boudrias, J.-S. (2017). On the merits of coherent leadership empowerment behaviors: A mixture regression approach. Journal of Vocational Behavior, 103, 66-75.

Chughtai, A., Byrne, M., \& Flood, B. (2015). Linking ethical leadership to employee well-being: The role of trust in supervisor. Journal of Business Ethics, 128, 653-663.

Collins, B.J., Burrus, C.J., \& Meyer, R.D. (2014). Gender differences in the impact of leadership styles on subordinate embeddedness and job satisfaction. The Leadership Quarterly, 25, 660-671.

Collins, M.D., \& Jackson, C.J. (2015). A process model of self-regulation and leadership: How attentional resource capacity and negative emotions influence constructive and destructive leadership. The Leadership Quarterly, 26, 386-401.

De Cremer, D. (2003). Why inconsistent leadership is regarded as procedurally unfair: The importance of social self- esteem concerns. European Journal of Social Psychology, 33, 535-550.

Diallo, T.M.O, Morin, A.J.S., \& Lu, H. (2016). Impact of misspecifications of the latent variancecovariance and residual matrices on the class enumeration accuracy of growth mixture models. Structural Equation Modeling, 23, 507-531.

Dienesch, R.M., \& Liden, R.C. (1986). Leader-member exchange model of leadership: A critique and further development. The Academy of Management Review, 11, 618-634.

Doden, W., Grote, G., \& Rigotti, T. (2018). Does leader-member exchange buffer or intensify detrimental reactions to psychological contract breach? The role of employees' career orientation. Journal of Vocational Behavior, 106, 192-208.

Eisenberger, R., Shoss, M.K., Karagonlar, G., Gonzalez- Morales, M.G., Wickham, R.E., \& Buffardi, L.C. (2014). The supervisor POS-LMX-subordinate POS chain: Moderation by reciprocation wariness and supervisor's organizational embodiment. Journal of Organizational Behavior, 35, 635-656.

Enders, C. (2010). Applied missing data analysis. Guilford. 
Finney, S.J., \& DiStefano, C. (2013). Non-normal and categorical data in structural equation modeling. In G.R. Hancock \& R.O. Mueller (Eds), Structural equation modeling: A second course $\left(2^{\text {nd }}\right.$ ed., pp. 439-492). IAP.

Flickinger, M., Allscher, M., \& Fiedler, M. (2016). The mediating role of leader-member exchange: A study of job satisfaction and turnover intentions in temporary work. Human Resource Management Journal, 26, 46-62.

Fouquereau, E., Morin, A.J.S., Lapointe, E., Mokounkolo, R., \& Gillet, N. (2019). Emotional labour profiles: Associations with key predictors and outcomes. Work \& Stress, 33, 268-294.

Gillet, N., Caesens, G., Morin, A.J.S., \& Stinglhamber, F. (2019b). Complementary variable- and person-centered approaches to the dimensionality of work engagement: A longitudinal investigation. European Journal of Work and Organizational Psychology, 28, 239-258.

Gillet, N., Fouquereau, E., Coillot, H., Bonnetain, F., Dupont, S., Moret, L., Anota, A., \& Colombat, P. (2018a). Ethical leadership, professional caregivers' well-being, and patients' perceptions of quality of care in oncology. European Journal of Oncology Nursing, 33, 1-7.

Gillet, N., Fouquereau, E., Vallerand, R.J., Abraham, J., \& Colombat, P. (2018b). The role of workers' motivational profiles in affective and organizational factors. Journal of Happiness Studies, 19, 11511174.

Gillet, N., Morin, A.J.S., Choisay, F. \& Fouquereau, E (2019b). A person-centered representation of basic need satisfaction balance at work. Journal of Personnel Psychology, 18, 113-128.

Gillet, N., Morin, A.J.S., \& Reeve, J. (2017). Stability, change, and implications of students' motivation profiles: A latent transition analysis. Contemporary Educational Psychology, 51, 222-239.

Gillet, N., Vallerand, R.J., Lafrenière, M.-A.K., \& Bureau, J.S. (2013). The mediating role of positive and negative affect in the situational motivation-performance relationship. Motivation and Emotion, 37, 465-479.

Goode, W.J. (1960). A theory of role strain. American Sociological Review, 25, 483-496.

Greguras, G.J., \& Ford, J.M. (2006). An examination of the multidimensionality of supervisor and subordinate perceptions of leader-member exchange. Journal of Occupational and Organizational Psychology, 79, 433-465.

Hart, D.W., \& Thompson, J.A. (2007). Untangling employee loyalty: A psychological contract perspective. Business Ethics Quarterly, 17, 297-323.

Hipp, J.R., \& Bauer, D.J. (2006). Local solutions in the estimation of growth mixture models. Psychological Methods, 11, 36-53.

Hobfoll, S.E. (1989). Conservation of resources: A new attempt at conceptualizing stress. American Psychologist, 44, 513-524.

Hobman, E.V., Restubog, S.L.D., Bordia, P., \& Tang, R.L. (2009). Abusive supervision in advising relationships: Investigating the role of social support. Applied Psychology, 58, 233- 256.

Holt-Lunstad, J., Uchino, B.N., Smith, T.W., Olson-Cerny, C., \& Nealey-Moore, J.B. (2003). Social relationships and ambulatory blood pressure: Structural and qualitative predictors of cardiovascular function during everyday social interactions. Health Psychology, 22, 388-397.

Honkavuo, L., \& Lindström, U.Å. (2014). Nurse leaders' responsibilities in supporting nurses experiencing difficult situations in clinical nursing. Journal of Nursing Management, 22, 117-126.

Kam, C., Morin, A.J.S., Meyer, J.P., \& Topolnytsky, L. (2016). Are commitment profiles stable and predictable? A latent transition analysis. Journal of Management, 42, 1462-1490.

Kasekende, F. (2017). Leader-member exchanges and psychological contract: Testing for interaction effects. Journal of Management Development, 36, 959-972.

Kim, T.-Y., Liu, Z., \& Diefendorff, J.M. (2015). Leader-member exchange and job performance: The effects of taking charge and organizational tenure. Journal of Organizational Behavior, 36, 216-231.

Kovacs, C., Batinic, B., Stiglbauer, B., \& Gnambs, T. (2019). Development of a shortened version of the latent and manifest benefits of work (LAMB) scale. European Journal of Psychological Assessment, 35, 685-697.

Lam, L.W., Xu, A.J., \& Loi, R. (2018). Is emotional engagement possible in emotionally demanding jobs? The role of leader-member exchange (LMX). Journal of Personnel Psychology, 17, 42-52.

Lanza S.T., Tan X., \& Bray B.C. (2013). Latent class analysis with distal outcomes: A flexible modelbased approach. Structural Equation Modeling, 20, 1-26.

Lee, J. (2008). Effects of leadership and leader-member exchange on innovativeness. Journal of 
Managerial Psychology, 23, 670-687.

Lian, H., Ferris, D.L., \& Brown, D.J. (2012). Does taking the good with the bad make things worse? How abusive supervision and leader-member exchange interact to impact need satisfaction and organizational deviance. Organizational Behavior and Human Decision Processes, 117, 41- 52.

Liao, S.-S., Hu, D.-Chian, Chung, Y.-C., \& Chen, L. (2017). LMX and employee satisfaction: Mediating effect of psychological capital. Leadership \& Organization Development Journal, 38, 433-449.

Liden, R.C., \& Maslyn, J.M. (1998). Multidimensionality of leader-member exchange: An empirical assessment through scale development. Journal of Management, 24, 43-72.

Lind, E.A., \& van den Bos, K. (2002). When fairness works: Toward a general theory of uncertainty management. Research in Organizational Behavior, 24, 181- 223.

Lo, Y., Mendell, N., \& Rubin, D. (2001). Testing the number of components in a normal mixture. Biometrika, 88, 767-778.

Major, B., \& Zubek, J.M. (1997). Mixed messages: Implications of social conflict and social support within close relationships for adjustment to a stressful life event. Journal of Personality and Social Psychology, 72, 1349- 1363.

Marchand, C., \& Vandenberghe, C. (2006). Perceived organizational support, emotional exhaustion, and turnover: The moderating role of negative affectivity. International Journal of Stress Management, 23, 350-375.

Marchese, M.C., \& Ryan, J. (2001). Capitalizing on the benefits of utilizing part-time employees through job autonomy. Journal of Business and Psychology, 15, 549-560.

Marsh, H.W., Lüdtke, O., Trautwein, U., \& Morin, A.J.S. (2009). Classical latent profile analysis of academic self-concept dimensions: Synergy of person- and variable-centered approaches to theoretical models of self-concept. Structural Equation Modeling, 16, 191-225.

Matta, F.K., Scott, B.A., Colquitt, J.A., Koopman, J., \& Passantino, L.G. (2017). Is consistently unfair better than sporadically fair? An investigation of justice variability and stress. Academy of Management Journal, 60, 743-770.

McLachlan, G., \& Peel, D. (2000). Finite mixture models. Wiley.

Meyer, J.P., \& Morin, A.J.S. (2016). A person-centered approach to commitment research: Theory, research, and methodology. Journal of Organizational Behavior, 37, 584-612.

Meyer, J.P., Allen, N.J., \& Smith, C.A. (1993). Commitment to organizations and occupations: Extension and test of a three-component conceptualization. Journal of Applied Psychology, 78, 538-551.

Montano, D., Reeske, A., Franke, F., \& Hüffmeier, J. (2017). Leadership, followers' mental health and job performance in organizations: A comprehensive meta-analysis from an occupational health perspective. Journal of Organizational Behavior, 38, 327-350.

Morganson, V.J., Major, D.A., \& Litano, M.L. (2017). A multilevel examination of the relationship between leader-member exchange and work-family outcomes. Journal of Business and Psychology, 32, 379-393.

Morin, A.J.S. (2016). Person-centered research strategies in commitment research. In J.P. Meyer (Ed.), The handbook of employee commitment (pp. 490-508). Edward Elgar.

Morin, A.J.S., Arens, A.K., \& Marsh, H. (2016a). A bifactor exploratory structural equation modeling framework for the identification of distinct sources of construct-relevant psychometric multidimensionality. Structural Equation Modeling, 23, 116-139.

Morin, A.J.S., Boudrias, J.-S., Marsh, H.W., Madore, I., \& Desrumaux, P. (2016b). Further reflections on disentangling shape and level effects in person-centered analyses: An illustration exploring the dimensionality of psychological health. Structural Equation Modeling, 23, 438-454.

Morin, A.J.S., Boudrias, J.-S., Marsh, H.W., McInerney, D.M., Dagenais-Desmarais, V., Madore, I., \& Litalien, D. (2017). Complementary variable- and person-centered approaches to the dimensionality of psychometric constructs: Application to psychological wellbeing at work. Journal of Business and Psychology, 32, 395-419.

Morin, A.J.S., Bujacz, A., \& Gagné, M. (2018). Person-centered methodologies in the organizational sciences: Introduction to the feature topic. Organizational Research Methods, 21, 803-813.

Morin, A.J.S., Maïano, C., Nagengast, B., Marsh, H.W., Morizot, J., \& Janosz, M. (2011a). Growth mixture modeling of adolescents trajectories of anxiety: The impact of untested invariance assumptions on substantive interpretations. Structural Equation Modeling, 18, 613-648.

Morin, A.J.S., Meyer, J.P., Creusier, J., \& Biétry, F. (2016c). Multiple-group analysis of similarity in latent 
profile solutions. Organizational Research Methods, 19, 231-254.

Morin, A.J.S., Morizot, J., Boudrias, J.-S., \& Madore, I. (2011b). A multifoci person-centered perspective on workplace affective commitment: A latent profile/factor mixture analysis. Organizational Research Methods, 14, 58-90.

Morin, A.J.S., Vandenberghe, C., Turmel, M., Madore, I., \& Maïano, C. (2013). Probing into commitment's nonlinear relationships to work outcomes. Journal of Managerial Psychology, 28, 202-223.

Morin, A.J.S., \& Wang, J.C.K. (2016). A gentle introduction to mixture modeling using physical fitness data. In N. Ntoumanis \& N. Myers (Eds.), An introduction to intermediate and advanced statistical analyses for sport and exercise scientists (pp. 183-210). Wiley.

Mullen, J., Kelloway, E.K., \& Teed, M. (2011). Inconsistent style of leadership as a predictor of safety behaviour. Work \& Stress, 25, 41-54.

Muthén, L.K., \& Muthén, B. (2017). Mplus user's guide. Muthén \& Muthén.

Olsson, L., Hemlin, S., \& Pousette, A. (2012). A multi-level analysis of leader-member exchange and creative performance in research groups. The Leadership Quarterly, 23, 604-619.

Paustian-Underdahl, S.C., King, E.B., Rogelberg, S.G., Kulich, C., \& Gentry, W.A. (2017). Perceptions of supervisor support: Resolving paradoxical patterns across gender and race. Journal of Occupational and Organizational Psychology, 90, 436-457.

Rhoades, L., \& Eisenberger, R. (2002). Perceived organizational support: A review of the literature. Journal of Applied Psychology, 87, 698-714.

Rockstuhl, T., Dulebohn, J.H., Ang, S., \& Shore, L.M. (2012). Leader-member exchange (LMX) and culture: A meta-analysis of correlates of LMX across 23 countries. Journal of Applied Psychology, 97, 1097-1130.

Rozin, P., \& Royzman, E.B. (2001). Negativity bias, negativity dominance, and contagion. Personality and Social Psychology Review, 5, 296-320.

Schaufeli, W.B., Leiter, M.P., Maslach, C., \& Jackson, S.E. (1996). The Maslach Burnout InventoryGeneral Survey. In C. Maslach, S.E. Jackson, \& M.P. Leiter (Eds.), Maslach Burnout Inventory $3^{\text {rd }}$ ed. (pp. 19-26). Consulting Psychologists Press.

Searle, R., Den Hartog, D.N., Weibel, A., Gillespie, N., Six, F., Hatzakis, T., \& Skinner, D. (2011). Trust in the employer: The role of high-involvement work practices and procedural justice in European organizations. International Journal of Human Resource Management, 22, 1069-1092.

Skrondal, A., \& Laake, P. (2001). Regression among factor scores. Psychometrika, 66, 563-576.

Sparks, K., Faragher, B., \& Cooper, C.L. (2001). Well- being and occupational health in the $21^{\text {st }}$ century workplace. Journal of Occupational and Organizational Psychology, 74, 489-509.

Spector, P.E., Rogelberg, S.G., Ryan, A.M., Schmitt, N., \& Zedeck, S. (2014). Moving the pendulum back to the middle: Reflections on and introduction to the inductive research special issue. Journal of Business \& Psychology, 29, 499-502.

Stewart, A., \& Ware, J.E. (1992). Measuring functioning and well-being - The medical outcomes study approach. Duke University Press.

Thomas, C.H., \& Lankau, M.J. (2009). Preventing burnout: The effects of LMX and mentoring on socialization, role stress, and burnout. Human Resource Management, 48, 417-432.

Thompson, E.R. (2007). Development and validation of an internationally reliable short-form of the Positive and Negative Affect Schedule (PANAS). Journal of Cross-Cultural Psychology, 38, 227-242.

Uchino, B.N., Holt-Lunstad, J., Uno, D., \& Flinders, J.B. (2001). Heterogeneity in the social networks of young and older adults: Prediction of mental health and cardiovascular reactivity during acute stress. Journal of Behavioral Medicine, 24, 361-382.

van den Bos, K., \& Lind, E.A. (2002). Uncertainty management by means of fairness judgments. Experimental Social Psychology, 34, 1- 60.

Van Katwyk, P.T., Fox, S., Spector, P.E., \& Kelloway, E.K. (2000). Using the Job-Related Affective Well-Being Scale (JAWS) to investigate affective responses to work stressors. Journal of Occupational Health Psychology, 5, 219-230.

Wang, M., Sinclair, R., \& Deese, M. (2010). Understanding the causes of destructive leadership behavior: A dual-process model. In B. Schyns \& T. Hansbrough (Eds.), When leadership goes wrong: Destructive leadership, mistakes, and failures (pp. 73-97). Information Age.

Watson, D., Clark, L.A., \& Tellegen, A. (1988). Development and validation of brief measures of positive and negative affect: The PANAS scales. Journal of Personality and Social Psychology, 54, 1063-1070. 
Xu, A.J., Loi, R., \& Chow, C.W.C. (2019). What threatens retail employees' thriving at work under leader-member exchange? The role of store spatial crowding and team negative affective tone. Human Resource Management, 58, 371-382.

Yagil, D., \& Medler-Liraz, H. (2017). Personally committed to emotional labor: Surface acting, emotional exhaustion and performance among service employees with a strong need to belong. Journal of Occupational Health Psychology, 22, 481-491. 


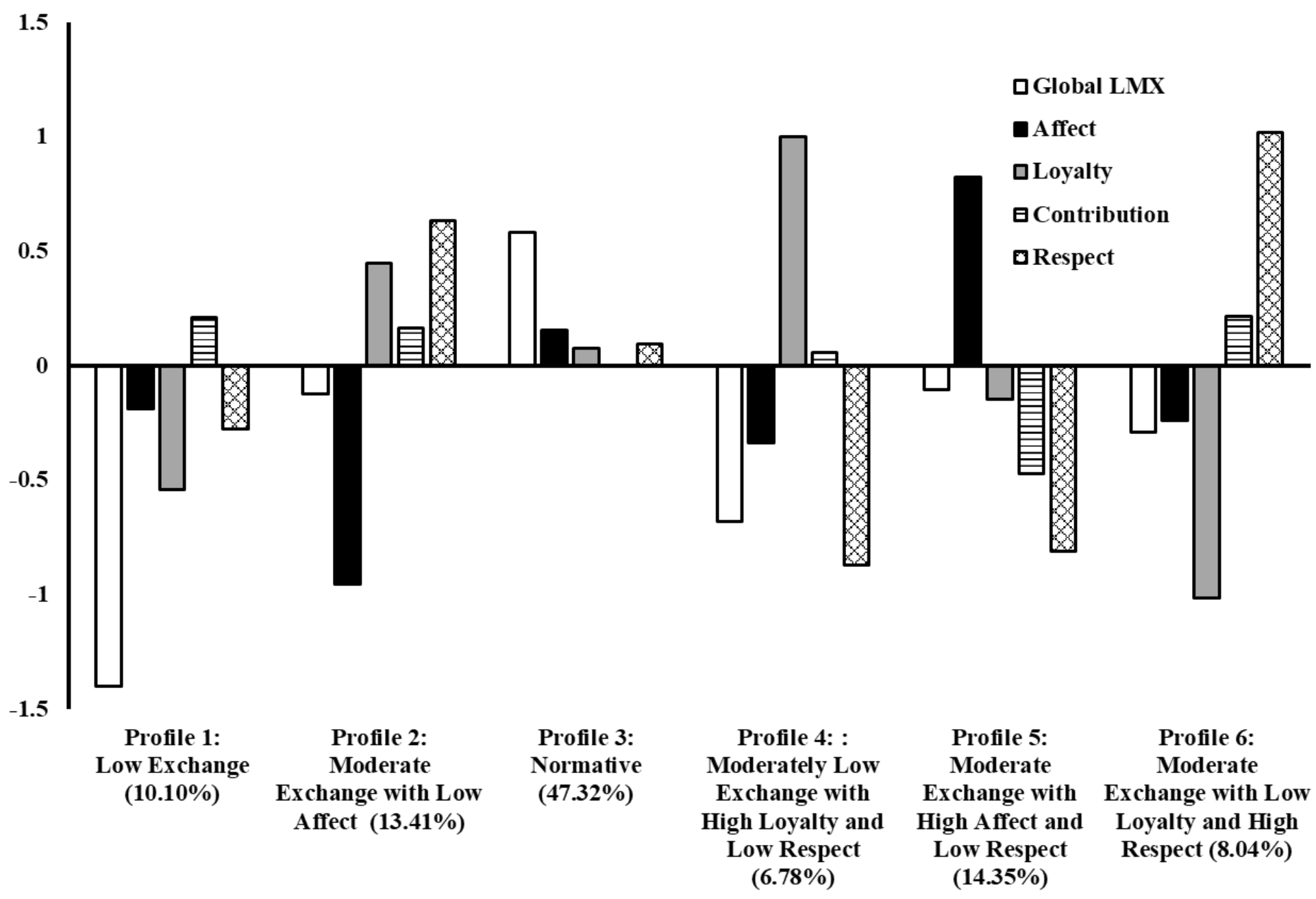

Figure 1. Final 6-Profile Solution Based on Bifactor Factor Scores

Note. Indicators are estimated from factor scores with a mean of 0 and a standard deviation of 1 


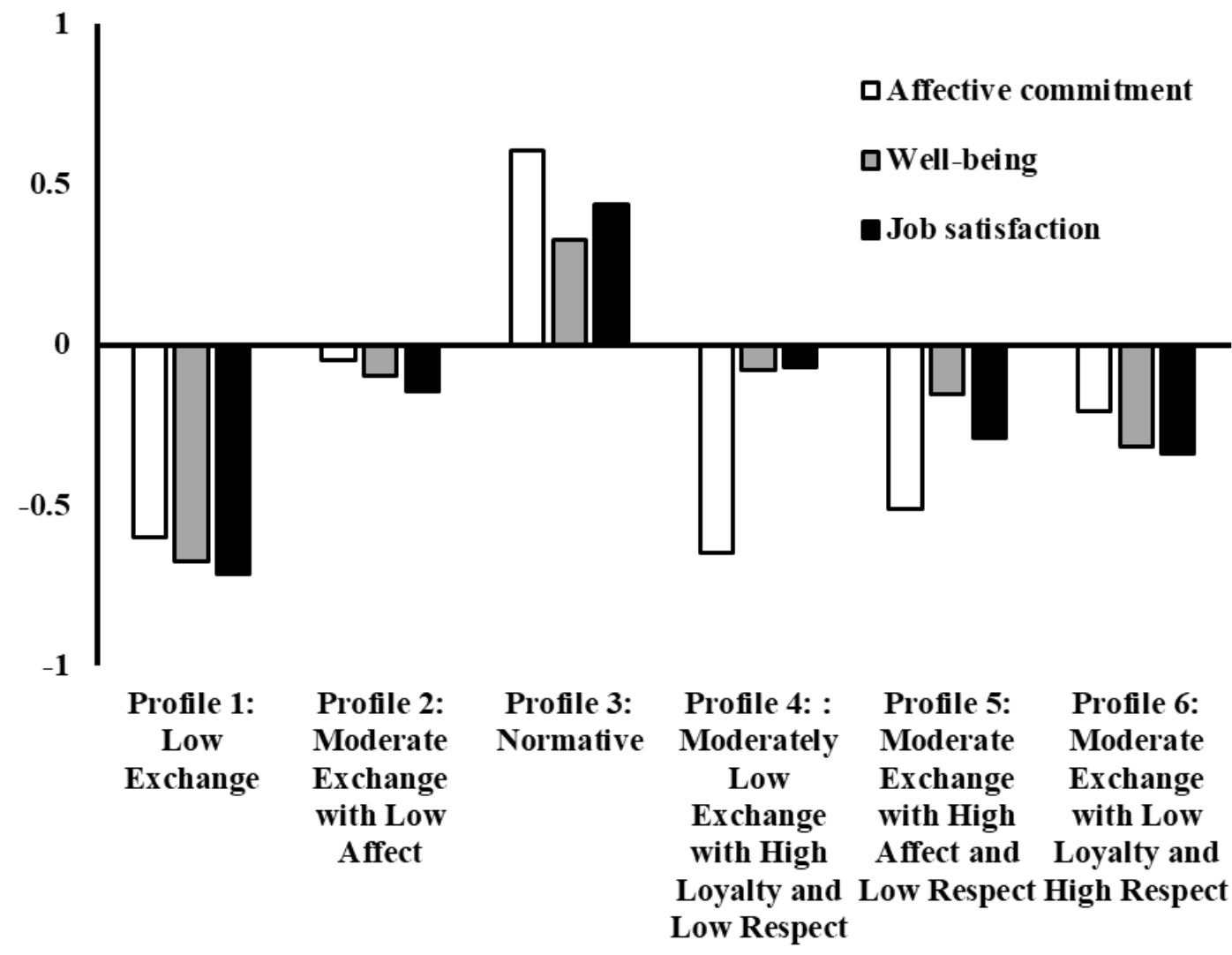

Figure 2. Outcome Levels (Affective Commitment, Well-Being, and Job Satisfaction) Note. Outcomes are estimated from factor scores with a mean of 0 and a standard deviation of 1.

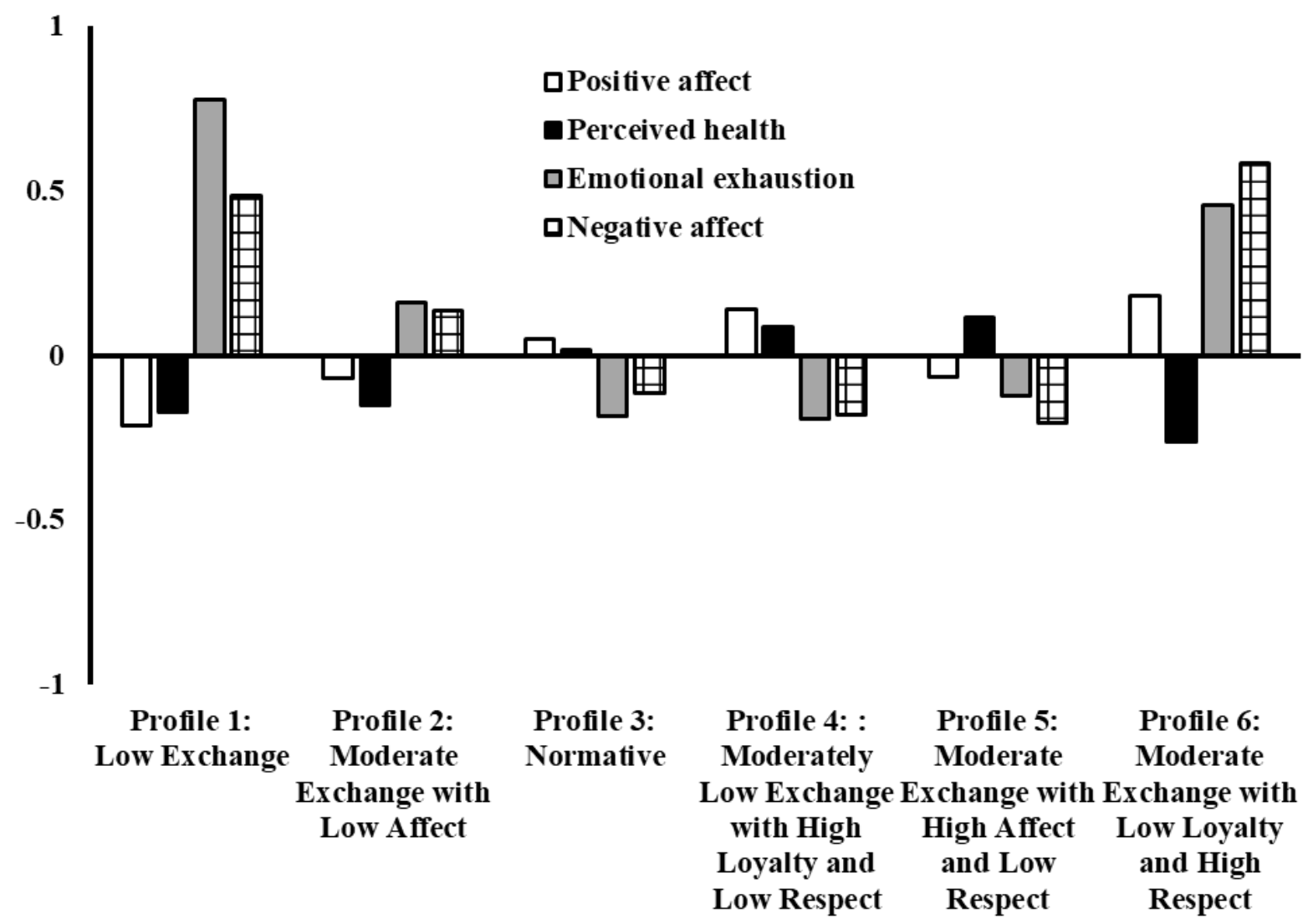

Figure 3. Outcome Levels (Positive and Negative Affect, Perceived Health, and Emotional Exhaustion) Note. Outcomes are estimated from factor scores with a mean of 0 and a standard deviation of 1. 


\section{Table 1}

Correlations between Variables

\begin{tabular}{|c|c|c|c|c|c|c|c|c|c|c|c|}
\hline & 1. & 2. & 3. & 4. & 5. & 6. & 7. & 8. & 9. & 10. & 11. \\
\hline 1. Global LMX (G-factor) ${ }^{1}$ & - & & & & & & & & & & \\
\hline 2. Specific affect (S-factor) & $.272 * *$ & - & & & & & & & & & \\
\hline 3. Specific loyalty (S-factor) & $.186 * *$ & $-.254 * *$ & - & & & & & & & & \\
\hline 4. Specific contribution (S-factor) & $.086^{*}$ & $-.231 * *$ & $-.136 * *$ & - & & & & & & & \\
\hline 5. Specific prof. respect (S-factor) & $.198 * *$ & $-.438 * *$ & $-.300 * *$ & .020 & - & & & & & & \\
\hline 6. Affective commitment & $.440 * *$ & .036 & $.084^{*}$ & $.228 * *$ & $.088 *$ & - & & & & & \\
\hline 7. Well-being & $.344 * *$ & .076 & $.092 *$ & $.150^{* *}$ & -.014 & $.581 * *$ & - & & & & \\
\hline 8. Emotional exhaustion & $-.249 * *$ & $-.112 * *$ & $-.122 * *$ & .047 & $.106^{* *}$ & $-.325 * *$ & $-.647 * *$ & - & & & \\
\hline 9. Job satisfaction & $.426 * *$ & $.085^{*}$ & $.118 * *$ & $.150 * *$ & .031 & $.712 * *$ & $.727 * *$ & $-.551 * *$ & - & & \\
\hline 10. Positive affect & $.150 * *$ & .048 & .036 & $.195 * *$ & -.022 & $.307 * *$ & $.533 * *$ & $-.230 * *$ & $.526 * *$ & - & \\
\hline 11. Negative affect & $-.213 * *$ & $-.133 * *$ & $-.099 *$ & -.036 & $.109 * *$ & $-.239 * *$ & $-.398 * *$ & $.553 * *$ & $-.444 * *$ & $-.426 * *$ & - \\
\hline 12. Perceived health & .035 & $.084 *$ & .029 & $-.096^{*}$ & -.077 & .074 & $.269 * *$ & $-.447 * *$ & $.277 * *$ & $.265 * *$ & $-.458 * *$ \\
\hline
\end{tabular}

Note. $* p<.05 ; * * p<.01 ;$ G-and S-factors: Global and specific factor scores estimated from a bifactor measurement model; all variables are estimated from factor scores with a mean of 0 and a standard deviation of 1 .

${ }^{1}$ Despite the orthogonality (all latent factors are uncorrelated) of the bifactor model from which factor score reflecting the LMX dimensions were extracted, the correlations reported in this Table involve factor scores which only provide an imperfect reflection of these latent correlations and thus display non-zero (rather than exactly 0) correlations. These correlations should not be interpreted. 
Table 2

Results from the Latent Profile Analysis Models

\begin{tabular}{lccccccccccc}
\hline Model & LL & $\# f p$ & Scaling & AIC & CAIC & BIC & ABIC & ICL-BIC & Entropy & aLMR & BLRT \\
\hline 1 Profile & -3749.720 & 10 & 1.036 & 7519.440 & 7573.960 & 7563.960 & 7532.211 & $\mathrm{Na}$ & $\mathrm{Na}$ & $\mathrm{Na}$ & $\mathrm{Na}$ \\
2 Profiles & -3689.241 & 16 & 1.162 & 7410.482 & 7497.715 & 7481.715 & 7430.916 & 7098.510 & .564 & $<.001$ & $<.001$ \\
3 Profiles & -3645.631 & 22 & 1.341 & 7335.262 & 7455.207 & 7433.207 & 7363.360 & 6956.787 & .658 & .108 & $<.001$ \\
4 Profiles & -3593.165 & 28 & 1.257 & 7242.330 & 7394.988 & 7366.988 & 7278.090 & 6825.579 & .692 & $<.001$ & $<.001$ \\
5 Profiles & -3560.025 & 34 & 1.418 & 7188.049 & 7373.419 & 7339.419 & 7231.472 & 6741.474 & .707 & .326 & $<.001$ \\
6 Profiles & -3530.925 & 40 & 1.568 & 7141.850 & 7359.932 & 7319.932 & 7192.936 & 6686.058 & .721 & .520 & $<.001$ \\
7 Profiles & -3502.936 & 46 & 1.523 & 7097.873 & 7348.667 & 7302.667 & 7156.621 & 6641.400 & .732 & .411 & $<.001$ \\
8 Profiles & -3475.908 & 52 & 1.444 & 7055.816 & 7339.323 & 7287.323 & 7122.228 & 6659.781 & .762 & .217 & $<.001$ \\
\hline
\end{tabular}

Note: LL: model LogLikelihood; \#fp: number of free parameters; Scaling: scaling factor associated with MLR loglikelihood estimates; AIC: Akaike Information Criteria; CAIC: constant AIC; BIC: Bayesian information criteria; ABIC: sample-size adjusted BIC; ICL-BIC: integrated classification likelihood BIC; aLMR: adjusted Lo-Mendel-Rubin likelihood ratio test; BLRT: bootstrap likelihood ratio test. 


\section{Table 3}

Associations between Profile Membership and the Covariates

\begin{tabular}{|c|c|c|c|c|c|c|c|}
\hline & $\begin{array}{c}\text { Profile } 1 \\
\text { Mean }[\mathrm{CI}]\end{array}$ & $\begin{array}{c}\text { Profile } 2 \\
\text { Mean }[\mathrm{CI}]\end{array}$ & $\begin{array}{c}\text { Profile } 3 \\
\text { Mean }[\mathrm{CI}]\end{array}$ & $\begin{array}{c}\text { Profile } 4 \\
\text { Mean }[\mathrm{CI}]\end{array}$ & $\begin{array}{l}\text { Profile } 5 \\
\text { Mean }[\mathrm{CI}]\end{array}$ & $\begin{array}{c}\text { Profile } 6 \\
\text { Mean }[\mathrm{CI}]\end{array}$ & Significant Differences \\
\hline Gender ( 0 male, 1 female) & $\begin{array}{c}.759 \\
{[.657 ; .861]}\end{array}$ & $\begin{array}{c}.718 \\
{[.622 ; .814]}\end{array}$ & $\begin{array}{c}.672 \\
{[.617 ; .727]}\end{array}$ & $\begin{array}{c}.619 \\
{[.482 ; .756]}\end{array}$ & $\begin{array}{c}.600 \\
{[.500 ; .700]}\end{array}$ & $\begin{array}{c}.677 \\
{[.555 ; .799]}\end{array}$ & $\begin{array}{l}1>5 ; 2=3=4=5=6 \\
1=2=3=4=6\end{array}$ \\
\hline Age (years) & $\begin{array}{c}37.913 \\
{[35.347 ; 40.479]}\end{array}$ & $\begin{array}{c}36.832 \\
{[34.453 ; 39.211]}\end{array}$ & $\begin{array}{c}38.584 \\
{[37.298 ; 39.870]}\end{array}$ & $\begin{array}{c}40.318 \\
{[37.305 ; 43.331]}\end{array}$ & $\begin{array}{c}39.801 \\
{[37.569 ; 42.033]}\end{array}$ & $\begin{array}{c}38.125 \\
{[35.216 ; 41.033]}\end{array}$ & $1=2=3=4=5=6$ \\
\hline Education $^{1}$ & $\begin{array}{c}3.252 \\
{[3.054 ; 3.450]}\end{array}$ & $\begin{array}{c}3.326 \\
{[3.150 ; 3.502]}\end{array}$ & $\begin{array}{c}3.345 \\
{[3.249 ; 3.441]}\end{array}$ & $\begin{array}{c}2.840 \\
{[2.560 ; 3.120]}\end{array}$ & $\begin{array}{c}3.513 \\
{[3.364 ; 3.662]}\end{array}$ & $\begin{array}{c}3.357 \\
{[3.143 ; 3.571]}\end{array}$ & $\begin{array}{l}1=2=3=6>4 ; 5>1 ; \\
2=3=5=6>4\end{array}$ \\
\hline Schedule ( 0 p. time, $1 \mathrm{f}$. time) & $\begin{array}{c}.818 \\
{[.728 ; .908]}\end{array}$ & $\begin{array}{c}.912 \\
{[.851 ; .973]}\end{array}$ & $\begin{array}{c}.805 \\
{[.760 ; .850]}\end{array}$ & $\begin{array}{c}.833 \\
{[.727 ; .939]}\end{array}$ & $\begin{array}{c}.872 \\
{[.801 ; .943]}\end{array}$ & $\begin{array}{c}.783 \\
{[.677 ; .889]}\end{array}$ & $\begin{array}{l}2>3=6 \\
1=3=4=5=6\end{array}$ \\
\hline Tenure: organization (years) & $\begin{array}{c}9.561 \\
{[7.381 ; 11.741]}\end{array}$ & $\begin{array}{c}11.767 \\
{[9.513 ; 14.021]}\end{array}$ & $\begin{array}{c}11.065 \\
{[9.877 ; 12.253]}\end{array}$ & $\begin{array}{c}12.506 \\
{[9.329 ; 15.683]}\end{array}$ & $\begin{array}{c}12.619 \\
{[10.404 ; 14.834]}\end{array}$ & $\begin{array}{c}10.719 \\
{[8.147 ; 13.291]}\end{array}$ & $1=2=3=4=5=6$ \\
\hline Tenure: position (years) & $\begin{array}{c}6.249 \\
{[4.783 ; 7.715]} \\
\end{array}$ & $\begin{array}{c}4.982 \\
{[3.861 ; 6.103]} \\
\end{array}$ & $\begin{array}{c}5.736 \\
{[5.058 ; 6.414]} \\
\end{array}$ & $\begin{array}{c}8.184 \\
{[6.157 ; 10.211]} \\
\end{array}$ & $\begin{array}{c}7.804 \\
{[6.242 ; 9.366]}\end{array}$ & $\begin{array}{c}5.389 \\
{[3.935 ; 6.843]}\end{array}$ & $\begin{array}{l}4=5>2=3=6 ; \\
1=4=5 ; 1=2=3=6\end{array}$ \\
\hline Affective commitment & $\begin{array}{c}-.601 \\
{[-.789 ;-.413]}\end{array}$ & $\begin{array}{c}-.050 \\
{[-.189 ; .089]}\end{array}$ & $\begin{array}{c}.604 \\
{[.500 ; .708]}\end{array}$ & $\begin{array}{c}-.650 \\
{[-.964 ;-.336]}\end{array}$ & $\begin{array}{c}-.511 \\
{[-.654 ;-.368]}\end{array}$ & $\begin{array}{c}-.206 \\
{[-.416 ; .004]}\end{array}$ & $3>2=6>1=4=5$ \\
\hline Well-being & $\begin{array}{c}-.675 \\
{[-.859 ;-.491]}\end{array}$ & $\begin{array}{c}-.095 \\
{[-.277 ; .087]}\end{array}$ & $\begin{array}{c}.326 \\
{[.222 ; .430]}\end{array}$ & $\begin{array}{c}-.080 \\
{[-.315 ; .155]}\end{array}$ & $\begin{array}{c}-.155 \\
{[-.314 ; .004]}\end{array}$ & $\begin{array}{c}-.319 \\
{[-.533 ;-.105]}\end{array}$ & $3>2=4=5=6>1$ \\
\hline Emotional exhaustion & {$[.552 ; 1.002]$} & {$[-.023 ; .345]$} & $\begin{array}{c}-.182 \\
{[-.280 ;-.084]}\end{array}$ & $\begin{array}{c}-.193 \\
{[-.424 ; .038]}\end{array}$ & $\begin{array}{c}-.123 \\
{[-.286 ; .040]}\end{array}$ & $\begin{array}{c}.455 \\
{[.230 ; .680]}\end{array}$ & $1>6>2>3=4=5$ \\
\hline Job satisfaction & $\begin{array}{c}-.713 \\
{[-.899 ;-.527]}\end{array}$ & $\begin{array}{c}-.144 \\
{[-.305 ; .017]}\end{array}$ & $\begin{array}{c}.437 \\
{[.337 ; .537]}\end{array}$ & $\begin{array}{c}-.072 \\
{[-.319 ; .175]}\end{array}$ & $\begin{array}{c}-.290 \\
{[-.435 ;-.145]}\end{array}$ & $\begin{array}{c}-.340 \\
{[-.556 ;-.124]}\end{array}$ & $3>2=4=5=6>1$ \\
\hline Positive affect & $\begin{array}{c}-.212 \\
{[-.398 ;-.026]}\end{array}$ & $\begin{array}{c}-.069 \\
{[-.247 ; .109]}\end{array}$ & $\begin{array}{c}.049 \\
{[-.053 ; .151]}\end{array}$ & {$[-.108 ; .390]$} & $\begin{array}{c}-.064 \\
{[-.233 ; .105]}\end{array}$ & $\begin{array}{c}.180 \\
{[-.083 ; .443]}\end{array}$ & $\begin{array}{l}3=4=6>1 ; \\
2=3=4=5=6\end{array}$ \\
\hline Negative affect & $\begin{array}{c}.484 \\
{[.288 ; .680]}\end{array}$ & $\begin{array}{c}.136 \\
{[-.046 ; .318]}\end{array}$ & $\begin{array}{c}-.115 \\
{[-.213 ;-.057]}\end{array}$ & $\begin{array}{c}-.178 \\
{[-.405 ; .049]}\end{array}$ & $\begin{array}{c}-.203 \\
{[-.368 ;-.038]}\end{array}$ & $\begin{array}{c}.585 \\
{[.326 ; .844]}\end{array}$ & $1=6>2>3=4=5$ \\
\hline Perceived health & $\begin{array}{c}-.172 \\
{[-.380 ; .036]}\end{array}$ & $\begin{array}{c}-.152 \\
{[-.334 ; .030]}\end{array}$ & $\begin{array}{c}.016 \\
{[-.084 ; .116]}\end{array}$ & $\begin{array}{c}.086 \\
{[-.153 ; .325]}\end{array}$ & $\begin{array}{c}.115 \\
{[-.054 ; .284]}\end{array}$ & $\begin{array}{c}-.261 \\
{[-.500 ;-.022]}\end{array}$ & $\begin{array}{l}5>1=2=6 ; 3=4>6 \\
1=2=3=4 ; 3=4=5 \\
1=2=6\end{array}$ \\
\hline
\end{tabular}

Note. CI $=95 \%$ confidence interval; affective commitment, well-being, emotional exhaustion, job satisfaction, positive affect, negative affect, and perceived health are estimated from factor scores with a standard deviation of 1 and a mean of $0 ;{ }^{1}$ : Education was coded 1 (no diploma), 2 (vocational training), 3 (high school), and 4

(University); Profile 1: Low Exchange; Profile 2: Moderate Exchange with Low Affect; Profile 3: Normative; Profile 4: Moderately Low Exchange with High Loyalty and Low Respect; Profile 5: Moderate Exchange with High Affect and Low Respect; Profile 6: Moderate Exchange with Low Loyalty and High Respect. 
Table 4

Summary Table

\begin{tabular}{|c|c|c|c|}
\hline Profile & Size & Description & Covariates \\
\hline P1 Low Exchange & $10.10 \%$ & $\begin{array}{l}\text { - Very low global LMX } \\
\text { - Moderately low affect, loyalty, and } \\
\text { respect } \\
\text { - Moderate contribution }\end{array}$ & $\begin{array}{l}\text { - Highest proportion of females ( } 75.9 \%) \text {. } \\
\text { - Lowest affective commitment (with P4 and P5), well-being, job } \\
\text { satisfaction, positive affect, and perceived health (with P2 and P6). } \\
\text { - Highest emotional exhaustion and negative affect (with P6). }\end{array}$ \\
\hline $\begin{array}{l}\text { P2 Moderate Exchange with Low } \\
\text { Affect }\end{array}$ & $13.41 \%$ & $\begin{array}{l}\text { - Average global LMX } \\
\text { - Average contribution } \\
\text { - Low affect } \\
\text { - Moderately high loyalty and respect }\end{array}$ & $\begin{array}{l}\text { - Highest proportion of full-time employees (91.2\%). } \\
\text { - Lowest tenure in position (4.98 years) with P3 and P6. } \\
\text { - Lowest perceived health (with P1 and P6). } \\
\text { - Lower emotional exhaustion than in P1 and P6. }\end{array}$ \\
\hline P3 Normative & $47.32 \%$ & $\begin{array}{l}\text { - Moderately high global LMX } \\
\text { - Average loyalty, affect, } \\
\text { contribution, and respect }\end{array}$ & $\begin{array}{l}\text { - Lowest proportion of full-time employees ( } 80.5 \% \text { ) with P6. } \\
\text { - Lowest tenure in position (5.74 years) with P2 and P6. } \\
\text { - Highest affective commitment, well-being, job satisfaction, positive } \\
\text { affect (with P4 and P6), and perceived health (with P4 and P5). } \\
\text { - Lowest emotional exhaustion (with P4 and P5) and negative affect } \\
\text { (with P4 and P5). }\end{array}$ \\
\hline $\begin{array}{l}\text { P4 Moderately Low Exchange with } \\
\text { High Loyalty and Low Respect }\end{array}$ & $6.78 \%$ & $\begin{array}{l}\text { - Low global LMX } \\
\text { - Low respect } \\
\text { - Moderately low affect } \\
\text { - Average contribution } \\
\text { - High loyalty }\end{array}$ & $\begin{array}{l}\text { - Lowest level of education }(M=2.84) \text {. } \\
\text { - Highest tenure in position }(8.18 \text { years) with P5. } \\
\text { - Lowest affective commitment (with P1 and P5), emotional } \\
\text { exhaustion (with P3 and P5), and negative affect (with P3 and P5). }\end{array}$ \\
\hline $\begin{array}{l}\text { P5 Moderate Exchange with High } \\
\text { Affect and Low Respect }\end{array}$ & $14.35 \%$ & $\begin{array}{l}\text { - Average global LMX } \\
\text { - Average loyalty } \\
\text { - Moderately low contribution } \\
\text { - Low respect } \\
\text { - High affect }\end{array}$ & $\begin{array}{l}\text { - Lowest proportion of females }(60.0 \%) \text {. } \\
\text { - Highest level of education }(M=3.51) \text {. } \\
\text { - Highest tenure in position }(7.80 \text { years) with P4. } \\
\text { - Lowest affective commitment (with P1 and P4), emotional } \\
\text { exhaustion (with P3 and P4), and negative affect (with P3 and P4). }\end{array}$ \\
\hline $\begin{array}{l}\text { P6 Moderate Exchange with Low } \\
\text { Loyalty and High Respect }\end{array}$ & $8.04 \%$ & $\begin{array}{l}\text { - Average global LMX } \\
\text { - Average affect and contribution } \\
\text { - Low loyalty } \\
\text { - High respect }\end{array}$ & $\begin{array}{l}\text { - Lowest proportion of full-time employees (78.3\%), with P3. } \\
\text { - Lowest tenure in position (5.39 years) with P2 and P3. } \\
\text { - Highest negative affect (with P1). } \\
\text { - Lowest perceived health (with P1 and P2). } \\
\text { - Higher emotional exhaustion than in P2, P3, P4, and P5. }\end{array}$ \\
\hline
\end{tabular}




\section{Online Supplemental Materials for: \\ A Person-Centered Perspective on the Combined Effects of Global and Specific LMX Components for Employees}

\section{Authors' note:}

These online technical appendices are to be posted on the journal website and hot-linked to the manuscript. If the journal does not offer this possibility, these materials can alternatively be posted on one of our personal websites (we will adjust the in-text reference upon acceptance).

We would also be happy to have some of these materials brought back into the main manuscript, or included as published appendices if you deem it useful. We developed these materials to provide additional technical information and to keep the main manuscript from becoming needlessly long. 


\section{Measurement Models}

CFA and bifactor-CFA representations of participants' LMX ratings were first estimated and contrasted in order to assess the need to incorporate a global LMX dimension underlying ratings provided by participants to all items ${ }^{1}$. In CFA, each item was only allowed to load on the factor it was assumed to measure and no cross-loading was allowed. This model included four correlated factors representing loyalty, affect, contribution, and professional respect. In bifactor-CFA, all items were allowed to simultaneously load on one G-factor reflecting global levels of LMX, and on four S-factors corresponding to specific levels of loyalty, affect, contribution, and professional respect. No cross-loading was allowed between the S-factors, and all factors were specified as orthogonal in line with bifactor assumptions (Morin, Arens, \& Marsh, 2016; Reise, 2012). Bifactor models disaggregate participants' ratings into one global component (the G-factor) reflecting the variance shared across all items, and into specific components (the S-factors) reflecting the variance shared among items forming a dimension not already explained by the G-factor.

Given the oversensitivity of the $\chi^{2}$ test of exact fit to sample size and minor misspecifications (Marsh, Hau, \& Grayson, 2005), we relied on goodness-of-fit indices to assess alternative models: The comparative fit index (CFI), the Tucker-Lewis index (TLI), and the root mean square error of approximation (RMSEA) with its $90 \%$ confidence interval. According to typical interpretation guidelines (e.g., Hu \& Bentler, 1999; Marsh, Hau, \& Wen, 2004; Marsh et al., 2005), values greater than .90 and .95 for the CFI and TLI respectively are considered to be indicative of adequate and excellent fit to the data, while values smaller than .08 or .06 for the RMSEA respectively support acceptable and excellent model fit. In the comparison of nested models, typical guidelines suggest that models differing from one another by less than .01 on the CFI and TLI, or .015 on the RMSEA, can be considered to provide an equivalent level of fit to the data (Chen, 2007; Cheung \& Rensvold, 2002).

As noted by Morin and colleagues (Morin, Arens, \& Marsh, 2016; Morin, Arens, Tran, \& Caci, 2016; Morin, Myers, \& Lee, in press), fit indices are not sufficient to guide the selection of the optimal model when first-order and bifactor CFA models are contrasted. An examination of parameter estimates and theoretical conformity is also required to select the best alternative. Specifically, the key elements supporting the bifactor representation are the observation of a greater level of fit to the data, a well-defined G-factor, and at least some reasonably well-defined S-factors. For all models, we report standardized parameter estimates and composite reliability coefficients calculated using McDonald (1970) omega (Morin et al., in press):

$$
\omega=\frac{\left(\sum\left|\lambda_{i}\right|\right)^{2}}{\left[\left(\sum\left|\lambda_{i}\right|\right)^{2}+\sum \delta_{i}\right]}
$$

where $\left|\lambda_{i}\right|$ are the standardized factor loadings in absolute values, and $\delta i$, the item uniquenesses.

Table S1 presents the fit of these measurement models. Parameter estimates for both solutions are reported in Table S2. The bifactor-CFA solution achieved an excellent fit to the data according to all indices, and a substantial increase in model fit relative to the CFA solution $(\Delta \mathrm{CFI}=+.010 ; \Delta \mathrm{TLI}=$ $+.011 ; \Delta$ RMSEA = -.010). Based on this statistical information, the bifactor-CFA solution should be retained. However, as noted above, model selection needs to be take into account parameter estimates and theoretical conformity. The bifactor-CFA resulted in a G-Factor well-defined by strong and positive loadings from all items $\left(\lambda=.320\right.$ to $\left..814 ; M_{\lambda}=.665, \omega=.948\right)$. Over and above this G-Factor, all items associated with the affect $\left(\lambda=.326\right.$ to $\left..423 ; M_{\lambda}=.385, \omega=.656\right)$, loyalty $\left(\lambda=.352\right.$ to $.558, M_{\lambda}$ $=.422, \omega=.627)$, contribution $\left(\lambda=.540\right.$ to $\left..731 ; M_{\lambda}=.633, \omega=.762\right)$, and professional respect $(\lambda=$ .466 to $\left..501 ; M_{\lambda}=.484, \omega=.741\right) \mathrm{S}$-factors retain a satisfactory level of specificity. Factor scores for the person-centered analyses were thus extracted from the bifactor-CFA solution.

\section{References}

Asparouhov, T., Muthén, B., \& Morin, A.J.S. (2015). Bayesian structural equation modeling with cross-loadings and residual covariances. Journal of Management, 41, 1561-1577.

\footnotetext{
${ }^{1}$ Following Morin, Arens, and Marsh's (2016; also see Morin, Arens, Tran, \& Caci, 2016) recommendations, these models were also contrasted with their Exploratory Structural Equation Modeling (ESEM) counterparts in which cross-loadings were freely estimated among first-order factors (in the ESEM solution) or among the S-factors (in the bifactor-ESEM solution). However, in the present study, there seemed to be very little added-value to the incorporation of cross-loadings to the solution: Most cross-loadings remained small $(\leq .100)$ and non-statistically significant, and ESEM solution ( $r=.451$ to .782$)$ resulted in virtually unchanged estimates of factor correlations when compared to CFA ( $r=.520$ to .794) (Asparouhov, Muthén, \& Morin, 2015).
} 
Chen, F.F. (2007). Sensitivity of goodness of fit indexes to lack of measurement. Structural Equation Modeling, 14, 464-504.

Cheung, G.W., \& Rensvold, R.B. (2002). Evaluating goodness-of-fit indexes for testing measurement invariance. Structural Equation Modeling, 9, 233-255.

Hu, L., \& Bentler, P.M. (1999). Cutoff criteria for fit indexes in covariance structure analysis: Conventional criteria versus new alternatives. Structural Equation Modeling, 6, 1-55.

Marsh, H.W., Hau, K.-T., \& Grayson, D. (2005). Goodness of fit evaluation in structural equation modeling. In A. Maydeu-Olivares \& J. McArdle (Eds.), Contemporary psychometric (pp. 275-340). Mahwah, NJ: Erlbaum.

Marsh, H.W., Hau, K.-T., \& Wen, Z. (2004). In search of golden rules: Comment on hypothesistesting approaches to cutoff values for fit indexes and dangers in overgeneralizing Hu \& Bentler's (1999) findings. Structural Equation Modeling, 11, 320-341.

McDonald, R. (1970). Theoretical foundations of principal factor analysis, canonical factor analysis, and alpha factor analysis. British Journal of Mathematical \& Statistical Psychology, 23, 1-21.

Morin, A.J.S., Arens, A.K., \& Marsh, H. (2016). A bifactor exploratory structural equation modeling framework for the identification of distinct sources of construct-relevant psychometric multidimensionality. Structural Equation Modeling, 23, 116-139.

Morin, A.J.S., Arens, A., Tran, A., \& Caci, H. (2016). Exploring sources of construct-relevant multidimensionality in psychiatric measurement: A tutorial and illustration using the Composite Scale of Morningness. International Journal of Methods in Psychiatric Research, 25, 277-288.

Morin, A.J.S., Myers, N.D., \& Lee, S. (in press). Modern factor analytic techniques: Bifactor models, exploratory structural equation modeling (ESEM) and bifactor-ESEM. In G. Tenenbaum \& R.C. Eklund (Eds.), Handbook of sport psychology, $4^{\text {th }}$ Edition. London, UK: Wiley

Reise, S.P. (2012). The rediscovery of bifactor measurement models. Multivariate Behavioral Research, 47, 667-696. 
Table S1

Goodness-of-Fit Statistics of the Preliminary Measurement Models

\begin{tabular}{lccccc}
\hline \multicolumn{1}{c}{ Description } & $\chi^{2}(d f)$ & CFI & TLI & RMSEA & $90 \%$ CI \\
\hline CFA & $131.121(48)^{*}$ & .978 & .970 & .052 & {$[.042 ; .063]$} \\
Bifactor-CFA & $89.389(42)^{*}$ & .988 & .981 & .042 & {$[.030 ; .054]$} \\
\hline
\end{tabular}

Note. ${ }^{*} p<.01 ; \mathrm{CFA}=$ confirmatory factor analyses; $\chi^{2}$ : robust chi-square test of exact fit; $d f$ : degrees of freedom; CFI: comparative fit index; TLI: Tucker-Lewis index; RMSEA: root mean square error of approximation; $90 \%$ CI: $90 \%$ confidence interval for the RMSEA.

Table S2

Standardized Factor Loadings $(\lambda)$ and Uniquenesses $(\delta)$ for the Preliminary Measurement Models

\begin{tabular}{|c|c|c|c|c|c|}
\hline & CFA & & B-CFA & & \\
\hline Items & $\lambda$ & $\delta$ & $\mathrm{G}-\lambda$ & $S-\lambda$ & $\delta$ \\
\hline \multicolumn{6}{|l|}{ Affect } \\
\hline Item 1 & .884 & .219 & .788 & .407 & .213 \\
\hline Item 2 & .854 & .271 & .752 & .423 & .256 \\
\hline Item 3 & .882 & .223 & .814 & .326 & .232 \\
\hline$\omega$ & .906 & & & .656 & \\
\hline \multicolumn{6}{|l|}{ Loyalty } \\
\hline Item 1 & .804 & .353 & .703 & .352 & .382 \\
\hline Item 2 & .862 & .256 & .717 & .558 & .174 \\
\hline Item 3 & .792 & .373 & .690 & .356 & .397 \\
\hline$\omega$ & .860 & & & .627 & \\
\hline \multicolumn{6}{|l|}{ Contribution } \\
\hline Item 1 & .638 & .592 & .320 & .627 & .505 \\
\hline Item 2 & .756 & .429 & .415 & .731 & .293 \\
\hline Item 3 & .881 & .224 & .619 & .540 & .326 \\
\hline$\omega$ & .806 & & & .762 & \\
\hline \multicolumn{6}{|l|}{ Respect } \\
\hline Item 1 & .833 & .306 & .673 & .501 & .296 \\
\hline Item 2 & .898 & .194 & .757 & .484 & .192 \\
\hline Item 3 & .871 & .241 & .730 & .466 & .249 \\
\hline$\omega$ & 901 & & .948 & .741 & \\
\hline
\end{tabular}

Note: $\mathrm{CFA}=$ confirmatory factor analyses; B-CFA = bifactor-CFA; G: global factor estimated as part of a bifactor model; $S$ : specific factor estimated as part of a bifactor model; $\lambda$ : factor loading; $\delta$ : item uniqueness; $\omega$ : omega coefficient of model-based composite reliability. 
Table S3

Standardized Factor Loadings $(\lambda)$, Uniquenesses $(\delta)$, and Latent Correlations for the Outcomes

\begin{tabular}{|c|c|c|c|c|c|c|c|c|}
\hline & AFF & WB & EE & SAT & POS & NEG & $\mathrm{PH}$ & \\
\hline Items & $\lambda$ & $\lambda$ & $\lambda$ & $\lambda$ & $\lambda$ & $\lambda$ & & $\delta$ \\
\hline AFF 1 & .879 & & & & & & & .227 \\
\hline AFF 2 & .846 & & & & & & & .285 \\
\hline AFF 3 & .903 & & & & & & & .184 \\
\hline AFF 4 & .872 & & & & & & & .240 \\
\hline AFF 5 & .791 & & & & & & & .375 \\
\hline AFF 6 & .848 & & & & & & & .281 \\
\hline WB 1 & & .675 & & & & & & .545 \\
\hline WB 2 & & .873 & & & & & & .239 \\
\hline WB 3 & & .738 & & & & & & .456 \\
\hline WB 4 & & .483 & & & & & & .767 \\
\hline WB 5 & & .622 & & & & & & .613 \\
\hline EE 1 & & & .784 & & & & & .385 \\
\hline EE 2 & & & .591 & & & & & .651 \\
\hline EE 3 & & & .835 & & & & & .302 \\
\hline EE 4 & & & .780 & & & & & .391 \\
\hline EE 5 & & & .759 & & & & & .423 \\
\hline SAT 1 & & & & .761 & & & & .421 \\
\hline SAT 2 & & & & .603 & & & & .636 \\
\hline SAT 3 & & & & .890 & & & & .208 \\
\hline POS 1 & & & & & .544 & & & .704 \\
\hline POS 2 & & & & & 648 & & & .580 \\
\hline POS 3 & & & & & .746 & & & .443 \\
\hline POS 4 & & & & & .531 & & & .718 \\
\hline POS 5 & & & & & .712 & & & .494 \\
\hline NEG 1 & & & & & & .737 & & .457 \\
\hline NEG 2 & & & & & & .582 & & .661 \\
\hline NEG 3 & & & & & & .714 & & .490 \\
\hline NEG 4 & & & & & & .783 & & .387 \\
\hline NEG 5 & & & & & & .647 & & .582 \\
\hline PH 1 & & & & & & & .807 & .349 \\
\hline PH 2 & & & & & & & .833 & .306 \\
\hline PH 3 & & & & & & & .832 & .309 \\
\hline PH 4 & & & & & & & .781 & .390 \\
\hline$\omega$ & .943 & .814 & .868 & .805 & .797 & .823 & 887 & \\
\hline Correlations & 1 & 2 & 3 & 4 & 5 & 6 & 7 & \\
\hline 1. AFF & - & & & & & & & \\
\hline 2. WB & .504 & - & & & & & & \\
\hline 3. $\mathrm{EE}$ & -.285 & -.566 & - & & & & & \\
\hline 4. SAT & .624 & .611 & -.493 & - & & & & \\
\hline 5. POS & .253 & .446 & -.167 & .439 & - & & & \\
\hline 6. NEG & -.205 & -.311 & .467 & -.374 & -.343 & - & & \\
\hline 7. PH & .052 & .212 & -.388 & .243 & .208 & -.380 & - & \\
\hline
\end{tabular}

Note: $\lambda$ : factor loading; $\delta$ : item uniqueness; non-significant parameters $(p \geq .05)$ are marked in italics; $\mathrm{AFF}=$ affective commitment; $\mathrm{WB}=$ well-being; $\mathrm{EE}=$ emotional exhaustion; $\mathrm{SAT}=$ job satisfaction; $\mathrm{POS}=$ positive affect $\mathrm{NEG}=$ negative affect $; \mathrm{PH}=$ perceived health . 


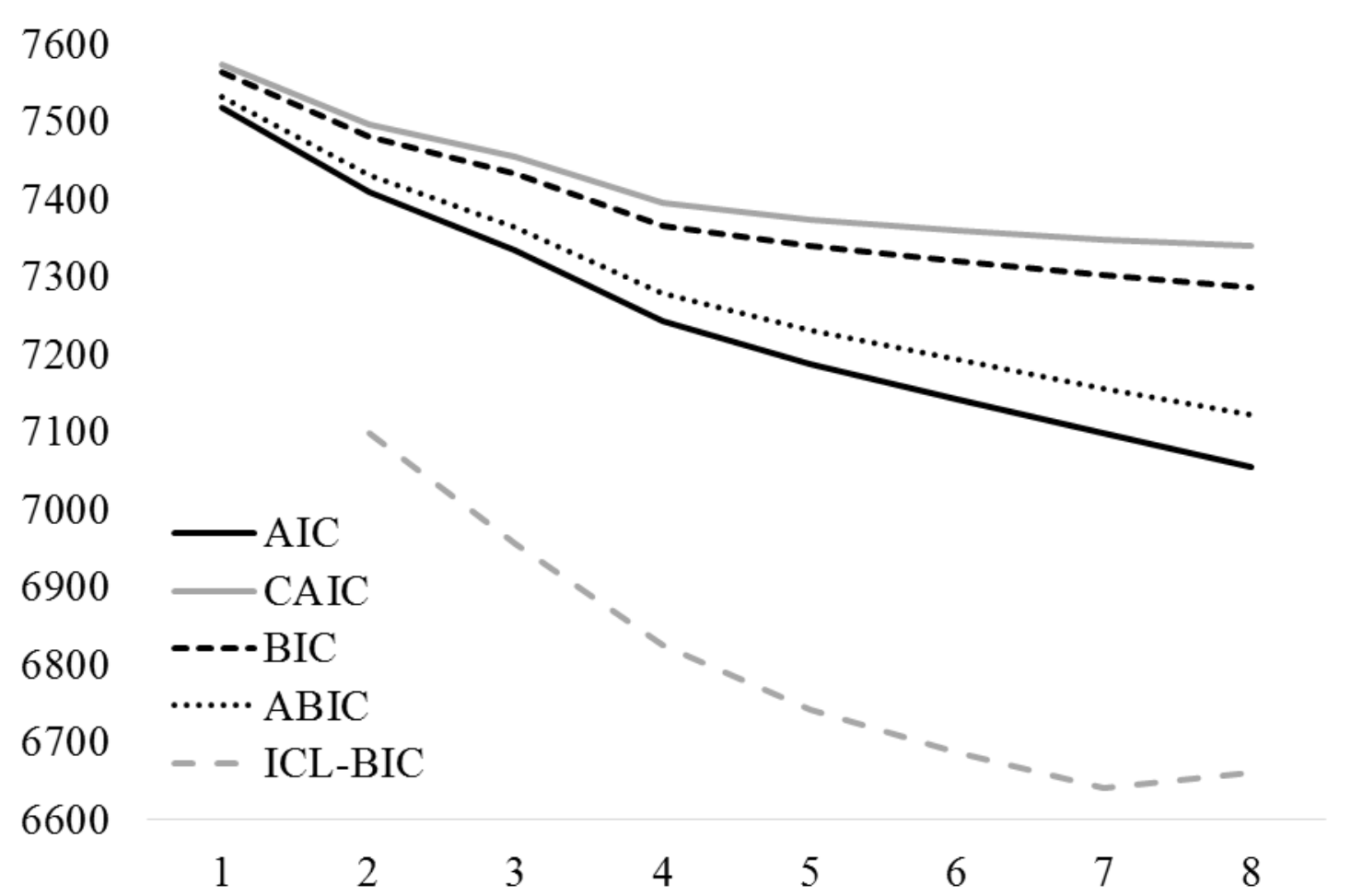

Figure S1

Elbow Plot of the Value of the Information Criteria for Solutions Including Different Number of Latent Profiles

Table S4

Detailed Results from the Final Latent Profile Solution

\begin{tabular}{|c|c|c|c|c|}
\hline & $\begin{array}{c}\text { Profile } 1 \\
\text { Mean }[\mathrm{CI}]\end{array}$ & $\begin{array}{c}\text { Profile } 2 \\
\text { Mean }[\mathrm{CI}]\end{array}$ & $\begin{array}{c}\text { Profile } 3 \\
\text { Mean }[\mathrm{CI}]\end{array}$ & $\begin{array}{c}\text { Profile } 4 \\
\text { Mean }[\mathrm{CI}]\end{array}$ \\
\hline$\overline{\text { Global }}$ & $-1.400[-1.652 ;-1.147]$ & $-.125[-.338 ; .089]$ & $.584[.458 ; .710]$ & $-.679[-1.344 ;-.013]$ \\
\hline Affect & $-.189[-.451 ; .073]$ & $\begin{array}{c}-.953[-1.216 ;- \\
.689]\end{array}$ & $.158[.032 ; .284]$ & $-.337[-.784 ; .110]$ \\
\hline Loya & $-.540[-.746 ;-.334]$ & $.449[.077 ; .822]$ & $.078[-.180 ; .336]$ & $.999[.639 ; 1.358]$ \\
\hline Contr & $.213[-.282 ; .708]$ & $.165[-.014 ; .345]$ & $.002[-.117 ; .121]$ & $.056[-.567 ; .680]$ \\
\hline \multirow[t]{2}{*}{ Respect } & $-.275[-.533 ;-.017]$ & $.632[.259 ; 1.006]$ & $.095[-.170 ; .360]$ & $-.870[-1$ \\
\hline & $\begin{array}{l}\text { Profile } 5 \\
\text { Mean }[\mathrm{CI}]\end{array}$ & $\begin{array}{c}\text { Profile } 6 \\
\text { Mean [CI] }\end{array}$ & Variance $[\mathrm{CI}]$ & \\
\hline$\overline{\text { Global }}$ & $-.103[-.479 ; .272]$ & $-.288[-1.086 ; .511]$ & $.460[.401 ; .518]$ & \\
\hline Affect & $.824[.623 ; 1.026]$ & $-.237[-.851 ; .377]$ & $.188[.155 ; .222]$ & \\
\hline Loyalty & $-.144[-.570 ; .282]$ & $\begin{array}{c}-1.012[-1.572 ;- \\
.452]\end{array}$ & $.341[.268 ; .415]$ & \\
\hline Contribut & $-.469[-.805 ;-.133]$ & $216[-.199 ; .631]$ & $.694[.604 ; .784]$ & \\
\hline Respect & $-.809[-1.112 ;-.506]$ & $1.017[.560 ; 1.474]$ & $.277[.227 ; .327]$ & \\
\hline \multicolumn{5}{|c|}{$\begin{array}{l}\text { Note. CI }=95 \% \text { confidence interval; the profile indicators are estimated from factor scores with a } \\
\text { mean of } 0 \text { and a standard deviation of 1; Profile 1: Low Exchange; Profile 2: Moderate Exchange with } \\
\text { Low Affect; Profile 3: Normative; Profile 4: Moderately Low Exchange with High Loyalty and Low } \\
\text { Respect; Profile 5: Moderate Exchange with High Affect and Low Respect; Profile 6: Moderate } \\
\text { Exchange with Low Loyalty and High Respect. }\end{array}$} \\
\hline
\end{tabular}


Table S5

Classification Accuracy: Average Probability of Membership into Each Latent Profile (Column) as a Function of the Most Likely Profile Membership (Row)

\begin{tabular}{lllllll}
\hline & Profile 1 & Profile 2 & Profile 3 & Profile 4 & Profile 5 & Profile 6 \\
\hline Profile 1 & .807 & .034 & .048 & .033 & .034 & .044 \\
Profile 2 & .013 & .783 & .120 & .038 & .000 & .045 \\
Profile 3 & .020 & .035 & .829 & .025 & .058 & .034 \\
Profile 4 & .064 & .028 & .093 & .770 & .045 & .000 \\
Profile 5 & .048 & .000 & .144 & .022 & .785 & .001 \\
Profile 6 & .074 & .055 & .100 & .000 & .007 & .764 \\
\hline
\end{tabular}

Note. The profile indicators are estimated from factor scores with a mean of 0 and a standard deviation of 1; Profile 1: Low Exchange; Profile 2: Moderate Exchange with Low Affect; Profile 3: Normative; Profile 4: Moderately Low Exchange with High Loyalty and Low Respect; Profile 5: Moderate Exchange with High Affect and Low Respect; Profile 6: Moderate Exchange with Low Loyalty and High Respect. 